\title{
The Role of the Patch/Striosome Component of the Dorsal Striatum in Spatial Learning
}

\author{
A thesis submitted to \\ the Faculty of Graduate Studies and Research \\ in partial fulfillment of the requirements for the degree \\ Masters of Science
}

by

Jeremy Nichol

Department of Psychology

Carleton University, Ottawa

January 2008

C2008 Jeremy Nichol 


$\begin{array}{ll}\begin{array}{l}\text { Library and } \\ \text { Archives Canada }\end{array} & \begin{array}{l}\text { Bibliothèque et } \\ \text { Archives Canada }\end{array} \\ \begin{array}{l}\text { Published Heritage } \\ \text { Branch }\end{array} & \begin{array}{l}\text { Direction du } \\ \text { Patrimoine de l'édition }\end{array} \\ \begin{array}{l}\text { 395 Wellington Street } \\ \text { Ottawa ON K1A 0N4 } \\ \text { Canada }\end{array} & \begin{array}{l}\text { 395, rue Wellington } \\ \text { Ottawa ON K1A ON4 }\end{array} \\ \text { Canada }\end{array}$

Your file Votre référence

ISBN: 978-0-494-36849-7

Ourfile Notre référence

ISBN: 978-0-494-36849-7

\section{NOTICE:}

The author has granted a nonexclusive license allowing Library and Archives Canada to reproduce, publish, archive, preserve, conserve, communicate to the public by telecommunication or on the Internet, loan, distribute and sell theses worldwide, for commercial or noncommercial purposes, in microform, paper, electronic and/or any other formats.

The author retains copyright ownership and moral rights in this thesis. Neither the thesis nor substantial extracts from it may be printed or otherwise reproduced without the author's permission.
AVIS:

L'auteur a accordé une licence non exclusive permettant à la Bibliothèque et Archives Canada de reproduire, publier, archiver, sauvegarder, conserver, transmettre au public par télécommunication ou par l'Internet, prêter, distribuer et vendre des thèses partout dans le monde, à des fins commerciales ou autres, sur support microforme, papier, électronique et/ou autres formats.

L'auteur conserve la propriété du droit d'auteur et des droits moraux qui protège cette thèse. $\mathrm{Ni}$ la thèse ni des extraits substantiels de celle-ci ne doivent être imprimés ou autrement reproduits sans son autorisation.
In compliance with the Canadian

Privacy Act some supporting forms may have been removed from this thesis.

While these forms may be included in the document page count, their removal does not represent any loss of content from the thesis.
Conformément à la loi canadienne sur la protection de la vie privée, quelques formulaires secondaires ont été enlevés de cette thèse.

Bien que ces formulaires aient inclus dans la pagination, il n'y aura aucun contenu manquant.

\section{Canadä}




\begin{abstract}
In the present thesis, the activity of neurons in the patch/striosome compartment, one of the two biochemically distinct components of the dorsal striatum, was inhibited using a chemical agonist selective for the mu-opioid receptors located there. This was done to test the hypothesis that the patch region may contribute to spatial learning and memory. Three experiments were carried out using the Morris water maze to investigate the role of the dorsal striatal patch compartment in spatial learning and memory function. Results of these experiments show that this striatal patch compartment does participate in spatial learning in a way that appears to be complementary to hippocampal function.
\end{abstract}




\section{Acknowledgments}

I would like to thank Dr. Matthew Holahan for his critical revisions of the draft and support and guidance throughout the project. I would like to acknowledge the assistance of Mr. Dan Madularu with much of the day to day work. I would also like to thank Dr. Hymie Anisman, and Dr. Alfonso Abizaid for their critical assistance. Finally I would like to thank Ms. Leana O'Byrne for her assistance in editing this thesis, and for being so supportive throughout. 


\section{Table of Contents}

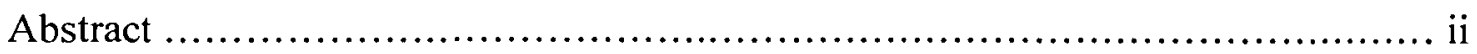

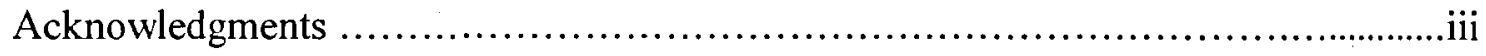

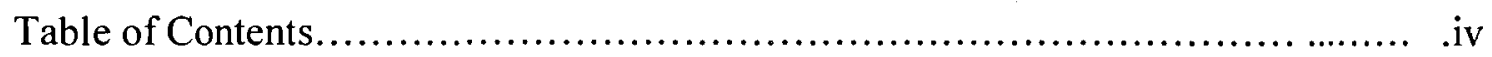

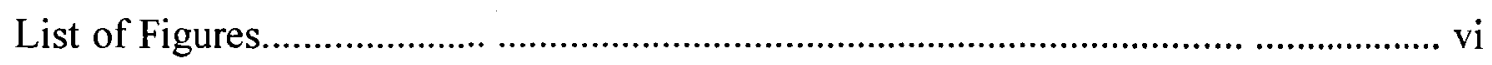

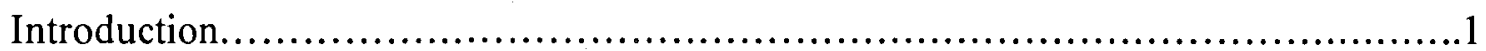

A Short Overview of Learning............................................. 1

Spatial Learning as a Form of Associative Learning.................................

Edward Tolman and the Origin of Spatial Learning...............................................

The Morris Water maze...........................................................................................

Hippocampal Place Cells.........................................................................................

Neural representation of space: limited to the Hippocampus?...............................

Localization of Spatial Learning: Other Systems.................................................10

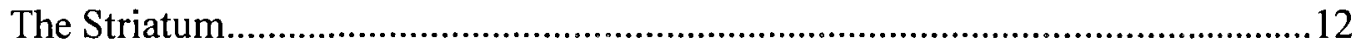

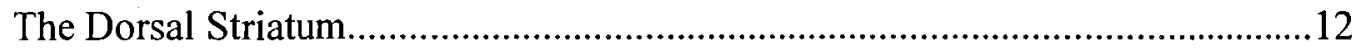

The Patch and Matrix: Anatomy and Biochemistry..............................................13

Functional Heterogeneity in the Striatum.........................................................15

The Role of the Patch in Spatial Learning............................................................16

Exclusive manipulation of the Patch.....................................................................16

Purpose of the Present Experiment...................................................................17

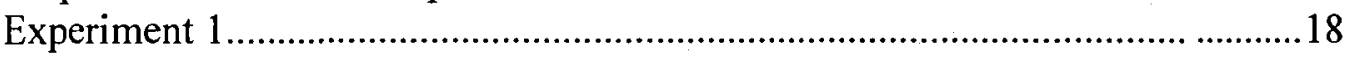

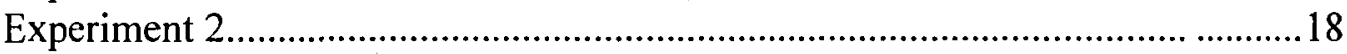

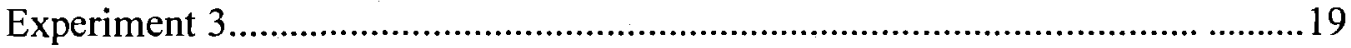

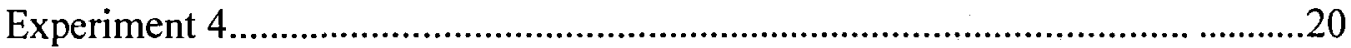

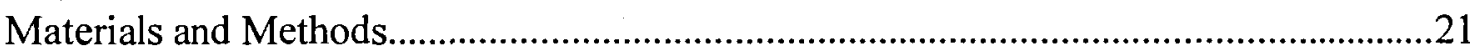

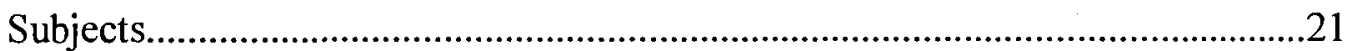

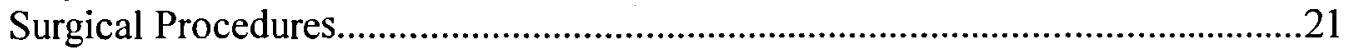

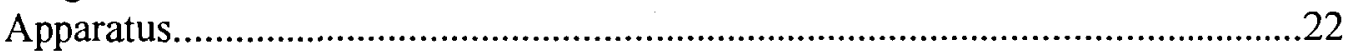

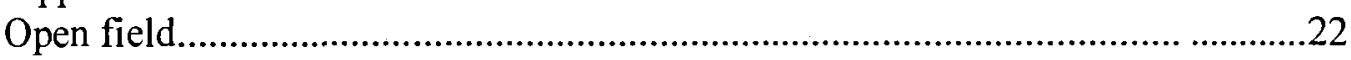

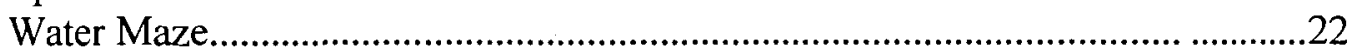

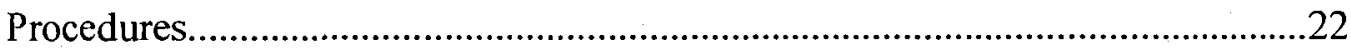

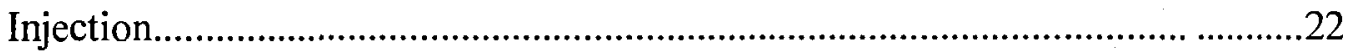

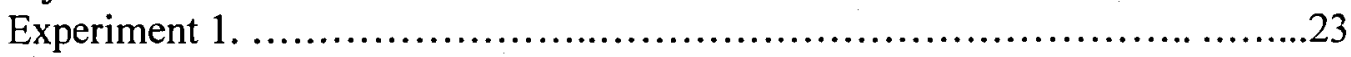

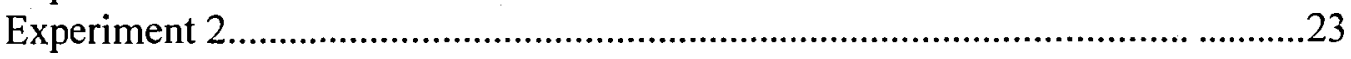




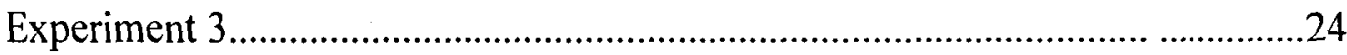

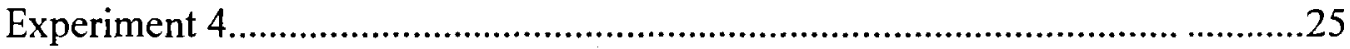

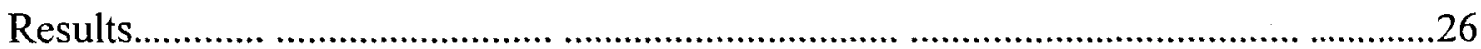

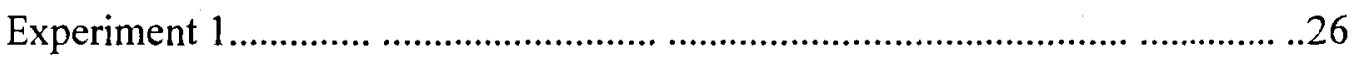

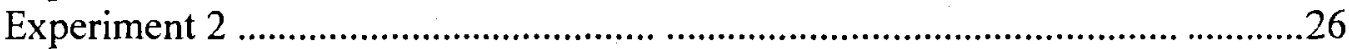

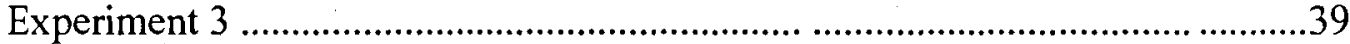

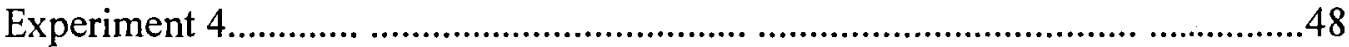

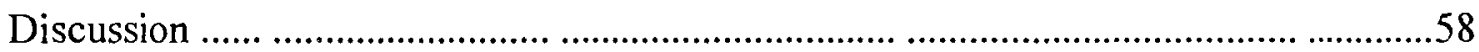

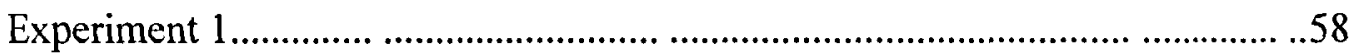

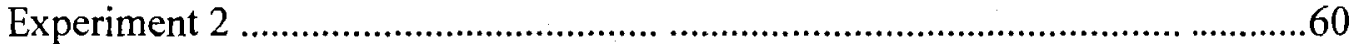

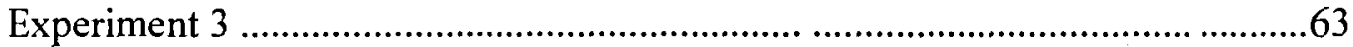

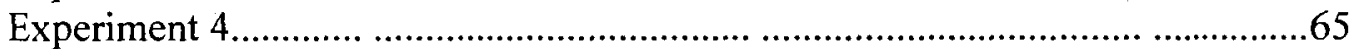

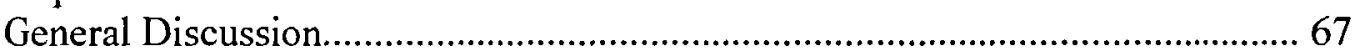

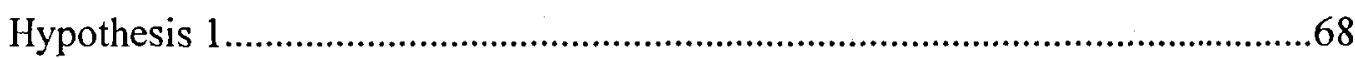

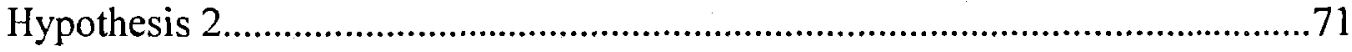

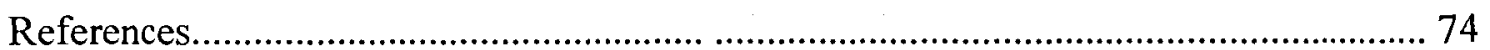




\section{List of Figures}

Figure 1

A raised maze with three paths of the type used by Tolman and Honzik (1930). ......4

Figure 2

The idealized learning curves of three groups $(a, b, c)$ in a latent learning experiment

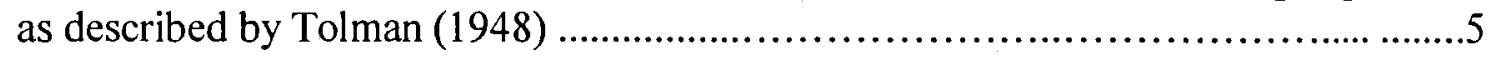

Figure 3

Representation of the cannula placements for the 24 Experiment 2 animals. 30

Figure 4

The average daily latency in seconds to reach a hidden platform by [3H]-DAMGO

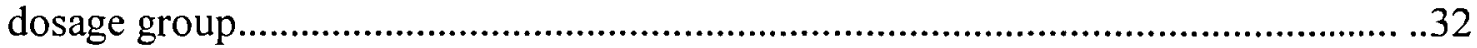

Figure 5

The average daily distance swum in centimetres to reach a hidden platform by each of the 4 groups

Figure 6

The average daily swimming velocity in centimetres per second to reach a hidden platform by $[3 \mathrm{H}]-\mathrm{DAMGO}$ dosage group.

Figure 7

Percent time spent in platform (target) quadrant per fifteen second interval..................38

Figure 8

Representation of the cannula placements for the 22 Experiment 3 animals

Figure 9

The average daily latency in seconds to reach a hidden platform by [3H]-DAMGO dosage group with no treatment administered...................................................43

Figure 10

The average latency in seconds to reach a hidden platform by [3H]-DAMGO dosage group by trial.

Figure 11

The Percent time spent in the two platform locations (initial and reversal) by [3H]DAMGO dosage group by fifteen second interval. 
Figure 12

Representation of the cannula placements for the 12 Experiment 3 animals....................51

Figure 13

The average daily latency in seconds to reach a hidden platform for Experiment 4 .........53

Figure 14

The average latency in seconds to reach a hidden platform location by trial in a platformswitching task following [3H]-DAMGO or saline injection............................................5

Figure 15

The latency in seconds to reach a hidden platform on the final trial of day 4 compared to

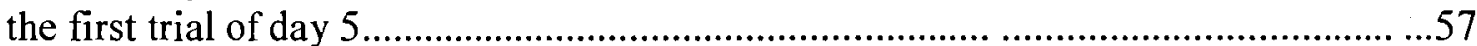




\section{Introduction}

The purpose of this thesis was to explore the associative process of spatial learning mediated by the patch/striosome compartment, a specific component of the dorsal striatum. The dorsal striatum is a brain region commonly associated with motor function and only recently has the possibility been put forth that this part of the brain mediates cognitive processes.

\section{A Short Overview of Learning}

Because, ultimately, all of our experience is derived through processes involved in brain plasticity, the full analysis of these processes is of critical importance to the understanding of the human condition. The epitome of brain plasticity, at some level, can be recognised as learning. Learning is the process of acquiring memories or experience (Kandel 2000). Learning is a broad field encompassing aspects of many disciplines from the specific electrophysiological and biochemical properties of receptors and membranes to the more general behavioural and cognitive psychological aspects of the organism as a whole with many overlapping layers of study in between. Learning has often been divided into two broad categories: non-associative and associative (Pear 2001). Nonassociative learning occurs when a repeated stimulus presentation leads to the modification of behaviour, whether through sensitization (increased response) or habituation (decreased response) (Pear 2001). Associative learning results from the experience of two stimuli occurring with some causal, temporal or spatial relation 
(Matthies 1989). Operant conditioning and classical (or Pavlovian) conditioning are both examples of associative learning.

\section{Spatial Learning as a form of associative learning}

Spatial learning is associative by nature and is defined as the acquisition of information about an individual's environment as well as the individual's position or orientation in that environment. Spatial learning is of critical importance to an individual's survival as it allows for the development of a neural conceptualization of the surroundings and personal position in those surroundings. This facilitates the organism's ability to move towards goals or away from dangers thereby increasing the chances of survival. A neural representation of the external environment allows an animal to move with precision to a goal even if the goal location was initially approached from a different starting point and the goal itself is not marked by an obvious cue. In other words, the animal does not have to move to the destination along a specific route but is able to plot a path from its new position based on a coordinate system and associations between external environmental stimuli. This can be seen in the ability of many species to return directly to a "home base" despite having deviated from a linear path several times and often with visual cues changed or gone (Etienne et al 1996). Therefore, spatial learning is associative by nature as animals learn associations between multiple cues in the environment to guide behavioural responses. 


\section{Edward Tolman, Stimulus-Stimulus learning, and the Origin of Spatial Learning}

The foundations for the study of spatial learning originated in the research of Edward Tolman, one of the first behaviourists to push for a stimulus-stimulus theory of associative learning. Stimulus-stimulus theory differed from the prevailing behaviourist stimulus-response theories of Thorndike (1911) and Hull (1943). Stimulus-response theory was the mechanistic view that behaviour (the response) arises from a drive (the stimulus) to satisfy physiological needs such as hunger or thirst (Hull 1943). Tolman's stimulus-stimulus theory complemented stimulus-response theory but differed in that there wasn't necessarily a one to one relationship between a stimulus and response. Instead, Tolman proposed that a stimulus could become associated with other stimuli and learning could occur without any reinforcement (Tolman 1932). These associations between stimuli would be elaborated in the brain where learning occurred (Tolman 1948). Tolman's addition of a cognitive element (the elaboration and association of stimuli in the brain) was contrary to the viewpoint of the stimulus-response theorists who felt that all behaviours could be explained through drives and the behaviours that resulted (Hull 1943).

Tolman theorised that one aspect of stimulus-stimulus learning was spatial learning, proposing that a cognitive map, or a field map, of the external environment was formed in the animal's brain through repeated interaction with the environment (Tolman 1948). Tolman demonstrated this idea with innovative experiments on rats navigating through various forms of dry mazes. Two particularly illustrative experiments were the raised arm maze and the latent learning experiment. With the former, Tolman devised a raised maze with three paths, as illustrated in figure 1 . 


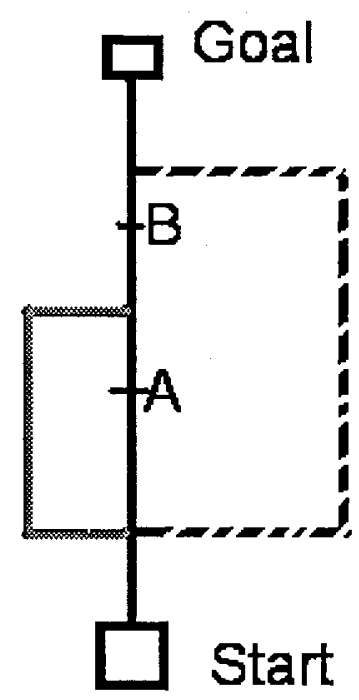

Figure 1. A raised maze with three paths of the type used by Tolman and Honzik (1930).

In this maze, the direct path (black) led directly from the start box to a goal box containing food reward. The second path (grey) branched away from the direct path and then returned to join it again at an intermediate point. The third and longest path (dashed line) also branched away from the direct path and then returned to rejoin it, in this case close to the reward position. Hungry rats trained in the maze reliably learned to run the direct route to the reward, learning to ignore the side passages, as predicted by stimulusresponse theory. If the direct route was blocked off at point " $\mathrm{A}$ ", forcing the rats to choose one of the side passages (where either path led successfully to the reward), the rats always chose the shorter path (grey). However, if the direct route was blocked at point " $\mathrm{B}$ ", so the only possible route was along the longest arm (dashed line), the rats began by running up the direct route to the block, but rather than attempt the grey arm next, the rats reliably ran down the long path (dashed line) to the reward, indicating that 
the rats had formed some internalized conception of the maze during their learning process (Tolman and Honzik 1930). As stated by Tolman, the rats "knew" that the grey path would also be sealed off with a block at position B. Stimulus-response theory would predict that with a block at the B point, rats would still turn around and run down the grey path as that was the next most associated set of responses with reward.

Tolman's concept of the cognitive or spatial map was also very effectively illustrated by a latent learning experiment. In this experiment, illustrated in figure 2 , three groups of rats $(a, b$, and $c)$ were run through a dry land maze.

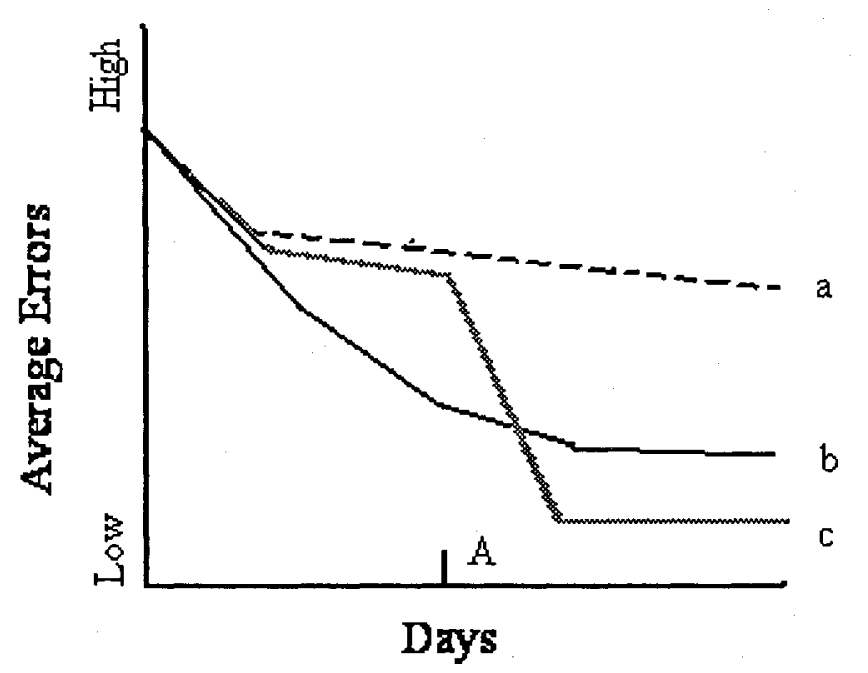

Figure 2. The idealized learning curves of three groups $(a, b, c)$ in a latent learning experiment as described by Tolman (1948).

The first group, group "a", never had a reward placed into the goal box and, although they showed some learning, consistently made a large number of errors in navigating the maze. Group "b" was always given a reward in the goal box and learned to navigate the maze with fewer and fewer mistakes gradually over days. Group "c" 
began the maze without a reward in the goal box for a learning period. However, at a point in time marked " $\mathrm{A}$ " in figure 2, a reward was introduced into the goal box resulting in an immediate and dramatic improvement in ability to navigate to the goal box. This startling observation indicated, to Tolman, that the rat had built up a spatial representation of the maze in its brain (Tolman 1948). These experiments provided initial evidence for the concept of spatial mapping.

\section{The Morris Water Maze}

The Morris water maze developed by Richard Morris in 1984 is understood to be a reliable and valid test of spatial learning and since its development has been frequently used to test the spatial abilities of rodents and humans (Morris 1984; D'Hooge and De Deyn 2001). The Morris Water maze is a task in which a rat or mouse must find a platform hidden below the surface of a pool filled with opaque water. The animal is released from random locations around the pool and it is thought that they navigate using spatial cues on the distant walls of the room to locate the hidden platform. In this design, there are no immediate or proximal cues marking the platform location. With repeated training, the animals require less time to locate the platform suggesting that the animal has developed an internal representation of the surrounding environment and is mentally positioning itself within that environment to plot a route towards the goal (i.e., the platform). 


\section{Hippocampal Place Cells}

In the early seventies, O'Keefe and Dostrovsky (1971) observed that specific neurons in the hippocampus increased their firing rates in response to the animal's location and orientation in a three dimensional coordinate system. Specific cells coding for an animal's position in the environment were thought to support the cognitive map theory. O'Keefe and Dostrovsky called the cells that fired in response to specific environmental locations "place cells". Place cells have been repeatedly observed since the O'Keefe and Dostrovsky finding and have been found in the principal cells of the CA1 and CA3 hippocampal regions as well as the granule cells of the dentate gyrus (O'Keefe 1993; Wilson and McNaughton 1993; Ekstrom et al 2003). Research on place cells has resulted in two major insights: 1) that there are many hippocampal cells that can all potentially contribute to the presentation of location through an increase in firing frequency when an animal is in a certain position in space (Wilson and McNaughton 1993) and 2) that place cells in the hippocampus may provide a neural representation of the organism's surroundings and therefore, one function of the hippocampus may be to create a cognitive map of the organism's environment (O'Keefe and Nadel 1978), or at minimum, play a critical role in spatial learning.

\section{Neural representation of space: limited to the Hippocampus?}

The discovery of place cells in the hippocampus was a powerful argument for the hippocampus as the brain structure where spatial learning takes place. However, research has demonstrated that the hippocampus is not responsible for the long-term storage of memory and also might not be the only structure responsible for spatial learning. 
Extensive studies of H.M., P.B., and others who have had through accident or surgery, the bilateral removal of their hippocampus (Scoville and Milner 1957; Milner 1970; Penfield and Milner 1970) have demonstrated that the hippocampus is not the site responsible for long-term memory storage. Researchers found that with removal of the hippocampus there is severe anterograde amnesia meaning that these patients cannot form new memories but that memories from long ago (e.g., remote memories) are intact. That the memory loss from hippocampal lesions does not affect memory that already exists suggests that the function of the hippocampus is for the learning of new information, while the long-term storage of those memories lies elsewhere (Nolte 1993; Milner et al 1998; Dash et al 2004). This suggests that the hippocampus functions with other structures in the storage of long-term memories.

In addition, evidence from animal literature has suggested that while the hippocampus plays a prominent role in spatial learning, it may do so in conjunction with other brain regions. Whishaw and colleagues (1995) severed the axons of the fimbriafornix (the major output for the hippocampus) and found that rats trained to find a hidden platform did not show much improvement in learning the spatial location. The authors concluded that this could be due to motor or other nonassociative issues resulting from a damaged hippocampus. To test this, they gave additional rats similar lesions and trained these rats to find a visible platform; a procedure thought to be easier for animals and therefore to be less sensitive to nonassociative factors. They found that hippocampallesioned animals learned the task similar to controls and when the platform was later removed, the rats showed evidence of spatial learning by circling the location where the platform had been located. These results were replicated in rats with hippocampal lesions 
restricted to the principal cells (Whishaw and Jarrard 1996). That hippocampal-lesioned rats were capable of showing spatial retention was a significant argument against the hippocampus as being the only structure responsible for spatial learning.

In another report (Saucier and Cain 1995) an N-methyl-D-aspartate (NMDA) receptor antagonist was used to block NMDA activity. This treatment resulted in a block of long-term potentiation (LTP) in the dentate gyrus of the hippocampus. LTP has long been thought to be a cellular mechanism of plasticity in the brain (Teyler and Discenna 1984; Kandel 2001). In the presence of successful LTP blockade, Saucier and Cain observed spatial learning in the water maze in animals who received non-spatial pretraining before receiving the NMDA antagonist. In a similar study, Bannerman (1995) also blocked NMDA activity and saw spatial learning if the animals were given pretraining. Consistently, a study by Cain and colleagues (1997) demonstrated that sensorimotor deficits caused by NMDA receptor blockade could account for many of the spatial learning deficits seen in Morris water maze task acquisition. Ahlander and colleagues (1999) also demonstrated the role of sensorimotor disturbances caused by NMDA blockade in the disturbance of spatial memory acquisition. All of these authors concluded that NMDA receptors and LTP were not the essential factors in the acquisition of spatial information. However, in the light of similar findings in the case of hippocampal or fimbria-fornix lesions, it may be that a dysfunctional hippocampus results in motor deficits, and spatial learning is at least partially intact.

Finally, in discussing the role of the hippocampus in spatial learning, it is important to consider that in the studies cited above, as well as in any study on learning involving lesions of the hippocampus, there has always been some spatial learning 
observed albeit at an impaired level compared to controls (see White et al 2003, for example). To rephrase, there is never a total block of spatial learning caused by hippocampal lesions. This suggests that there must be other brain structures involved in spatial learning whether through redundant or entirely independent systems of the hippocampus.

\section{Localization of Spatial Learning: Other Systems}

There are several pieces of direct evidence supporting the notion that brain regions beyond the hippocampus are involved in spatial learning. These additional systems have been argued to work in series (Devan and White 1999) independently (McDonald and White 1993; McDonald and White 1994; McDonald et al 2004) or redundantly (Knierim 2006) with the hippocampus. One demonstration for extrahippocampal learning is in findings of place cells in extra-hippocampal locations including the entorhinal cortex (Quirk et al 1992; Fyhn 2004), the mammillary bodies (Vann and Aggleton 2004), the subiculum (Sharp 1996), the septum (Zhou et al 1999) and the striatum (Yeshenko et al 2004).

Another piece of evidence for extra-hippocampal learning is that anterograde amnesia, similar to that found in cases of lesions or damage to the hippocampus, is also seen in Korsakoff's syndrome. Korsakoff's syndrome is a form of brain damage resulting from thiamine deficiency seen in situations such as alcohol abuse. Damage in Korsakoff's syndrome may be throughout the medial temporal lobe or in pathways to and from the hippocampus (Nolte 1993). Because these are overlapping regions of damage, this could simply indicate that the amnesia may be essentially the same as is caused from 
hippocampal lesions. However, the damage in Korsakoff's syndrome can also be found throughout the mammillary bodies, and in some cases, the pathology is found exclusively there (Vann and Aggleton 2004). That damage to the mammillary bodies, without associated damage to the hippocampus, can cause memory loss mimicking that seen with hippocanpal damage leads to an important conclusion: that learning and memory likely have independent or redundant systems throughout regions of the brain.

There is further evidence for extra-hippocampal learning in the identification of regions vital to the consolidation of memory. These regions include many brain structures with direct and indirect connections to the hippocampus. Structures with direct connection to the hippocampus include the parahippocampal cortex and the septum (Knierim 2006). Other structures with connections to the hippocampus include the mammillary bodies (Vann and Aggleton 2004), the neocortex (Maviel et al 2004) and the dorsal striatum (Devan and White 1999). Lesions or NMDA receptor blockade in these regions have been found to result in memory deficits. Holmes, Jacobson, Stein, and Butters (1983), for example, found that monkeys with their mammillary bodies lesioned were severely impaired in a spatial memory retention task. Ramirez and colleagues (2007) found that bilateral lesions of the entorhinal cortex in rats led to an inability to learn a spatial task. Devan and White (1999) found that lesions to the medial dorsal striatum in rats slowed the acquisition of a platform location in the water maze task and that animals with lesions of the dorsal striatum demonstrated a preference for the visible over the spatial location of a platform in a competition task. These authors suggested the medial dorsal striatum might be part of a memory system involving the hippocampus. These results were reinforced by the finding that NMDA receptor blockade in the medial 
dorsal striatum caused a similar loss of long-term retention of spatial information as NMDA blockade in the hippocampus (Holahan et al 2005). With this evidence it is clear that other brain systems are playing some role in spatial learning.

\section{The Striatum}

The striatum can be seen as the region of the basal ganglia composed of the globus pallidus, the substantia nigra pars reticula, the caudate nucleus and the putamen (Nolte 1993), or by the more stringent view as the nucleus of the caudate and the putamen (Voorn et al 2004). The more prevalent view, however, is the view that will be used for this paper; that the striatum comprises the caudate nucleus, the putamen and the nucleus accumbens (the nucleus accumbens is also known as the ventral striatum) (Nauta 1979; Parent et al 2000; Conn 2003). The two most prominent inputs that the striatum receives are glutamatergic and therefore excitatory. The excitatory connection from the cerebral cortex flows out from the striatum to the thalamus before returning to the cortex (Conn 2003). The second excitatory input to the striatum is from the intralaminar nuclei of the thalamus. The striatum also receives dopaminergic and serotonergic inputs. From the substantia nigra, there is an excitatory dopaminergic connection. From the raphe nucleus, projecting mainly to the nucleus accumbens, is an inhibitory serotonergic connection (Nolte 1993).

\section{The Dorsal Striatum}

Within the striatum, the caudate and putamen together are called the neo-striatum, or dorsal striatum. In primates and carnivores, the internal capsule clearly separates the 
caudate and putamen, but despite this physical separation, they are considered to have the same internal composition (Nauta 1979; Fentress et al 1981). In rats, there is no separation of the caudate and the putamen by the internal capsule so they are together termed the caudoputamen (Fentress et al 1981; Heimer et al 1985).

In terms of cytoarchitecture, the striatum is mainly composed of medium size spiny cells (Wilson et al 1990). Despite this homology, there is evidence of a division internally between the dorsomedial and dorsolateral regions. Neocortical somatosensory and motor areas have been found to project to the dorsolateral part of the striatum, whereas visual and auditory cortical areas have been found to project primarily to the dorsomedial striatum (Donoghue and Herkenham 1986). There is also a heterogeneous mixture of different neurotransmitters present and the allocation of neurotransmitters has been demonstrated to be distributed in biochemically specialized and distinct compartments (Graybiel and Ragsdale 1978; Graybiel 1990). The two divisions of the striatum are known as the patch (also called the striosome) and the matrix.

\section{The Patch and Matrix: Anatomy and Biochemistry}

While staining for acetylcholinesterase in the basal ganglia Graybiel and Ragsdale (1978) were the first to make the discovery that there were acetylcholinesterase-low regions scattered throughout a matrix of acetylcholinesterase-rich neurons in the dorsal striatum of humans, monkeys and cats. Since this discovery, many findings have confirmed the presence of the two regions and given a clearer picture of their anatomy and biochemistry (Graybiel 1990). The acetylcholinesterase-poor regions are called "patches" or "striosomes" and run like channels, or tunnels, on the mediolateral axis 
through the surrounding striatum (Desban et al 1993), which is acetylcholinesterase rich and known as the matrix. Further, there was found to be significantly more matrix in the posterior and lateral dorsal striatum and more patch in the anterior and medial dorsal striatum (Krebs et al 1991). Conn (2003) reported similar neuroanatomical results, noting that the majority of inputs from the motor cortex are primarily to the matrix rather than the patch regions. Also noted was that inputs from the thalamus are mainly to the matrix (Conn 2003).

Although the neurons of the striatum are primarily GABAergic (Wichmann and DeLong 1996), and therefore inhibitory, biochemically, there are considerable differences between the patch and the matrix regions. As noted, the matrix compartment is frequently identified by acetylcholinesterase-rich histochemistry, while the patch has been found to be acetylcholinesterase-poor (Graybiel and Ragsdale 1978). An intensive meta-analysis by Graybiel (1990) found the biochemical makeup of the matrix included exclusively $\mathrm{D}_{2}$ dopaminergic binding sites, choline uptake sites, serotonin immunoreativity and the presence of enkephalin. The patches were found to be substantially different with $D_{1}$ dopaminergic binding sites, $M_{1}$ cholinergic binding sites, benzodiazepine binding sites and the presence of dynorphin and neurotensin. Further biochemical differences are evident from the ability to identify patches by labelling with ${ }^{3} \mathrm{H}$-naloxone- and ${ }^{3} \mathrm{H}$-diprenorphine, as the patch is rich in Mu-opiate receptors (Desban et al 1993). 


\section{Functional Heterogeneity in the Striatum}

Because the inputs to the lateral striatum or matrix are primarily from the motor cortex and also because the onset of the motor symptoms of Parkinson's disease follows destruction of the dopaminergic nigrostriatal pathway in the basal ganglia, the basal ganglia region has long been assumed to be responsible for various motor functions (Nolte 1993). More recently, this view has been changed to take into account evidence such as cognitive impairments caused by diseases produced by degeneration of the striatum (Brown et al 1997). It is now accepted that the striatum is responsible for both cognitive and motor processes, though the understanding of the specifics of these processes to particular subdivisions of the striatum remains uncertain.

Structural differences tend to parallel functional differences and given the evidence of structural heterogeneity noted above, it is no surprise that there is evidence of functional heterogeneity in the striatum and that this heterogeneity correlates well with the incidence of patch and matrix regions. As noted, there is a division between the medial and lateral regions of the dorsal striatum in terms of inputs, where inputs to the lateral regions are primarily from the neocortical somatosensory and motor areas and inputs to the medial striatum are predominantly from the visual and auditory cortical areas (Donoghue and Herkenham 1986). This correlates well with a preponderance of patch region in the anterior and medial regions of the striatum and a preponderance of matrix in the posterior and lateral striatum (Graybiel 1990). The distribution of inputs to areas of differing incidence of patch and matrix indicate a functional division between the patch and matrix where the matrix is potentially more involved in motor function and the patch potentially plays a role in cognitive functions. Further, there is strong evidence for 
indirect projections from the hippocampus to the striatum with this projection terminating in the more medial (patch) rather than lateral (matrix) aspects (Devan and White 1999). Experimental evidence with animals also confirms this heterogeneity between regions rich in matrix and regions rich in patch. For example, Devan and White (1999) found that rats with medial-striatal lesions had spatial deficits possibly due to a loss of the region rich in patch. The same study found that lesions of the lateral striatum, the region rich in matrix, blocked cued learning or S-R learning.

\section{The Role of the Patch in Spatial Learning}

The experimental evidence of heterogeneity in structure and function between regions rich in matrix and regions rich in patch indicates that the patch component of the dorsal striatum is functionally different than the matrix. Based on conjecture and its role in cognitive processes the patch is thought to play some role in spatial learning. However, the precise role has not been clearly demonstrated. The function of the patch could be as a parallel system, whether redundant or independent (McDonald and White 1993; Chang and Gold 2003; McDonald et al 2004; Holahan et al 2005) of the hippocampus during spatial information processing. Alternatively, the patch may act as part of a serial pathway in concert with the hippocampus (Devan and White 1999).

\section{Exclusive manipulation of the Patch: [3H]-DAMGO and mu-Receptors}

If the patch plays a role in spatial learning, exclusive blockade of the patch component of the dorsal striatum should result in deficits in some, or possibly all, aspects of spatial learning. Because evidence has shown that the patch and matrix components of 
the dorsal striatum have different neurochemical make-up, the exclusive blockade of the patch should be possible. One major difference between the patch and the matrix is that the patch is enriched in mu-opioid receptors whereas the matrix component of the dorsal striatum is virtually free from this receptor type (Graybiel 1990; Wang et al 1997). As a result, specific manipulations of the patch could be possible given a compound that could interact specifically with the mu-opioid receptors.

Activation of mu-opioid receptors leads to an inhibition of the firing potential of a neuron (Schroeder et al 1990) indicating that the mu-opioid receptors are inhibitory in nature. Because of this, and because the mu-opioid receptors are found exclusively in the patch region of the striatum, an effective agonist for the mu-opioid receptor delivered to the dorsal striatum would result in an overall decrease of patch neuronal firing. A highly effective agonist of the mu-receptor has been developed, [3H]-[D-Ala2,MePhe4,Glyol5]-enkephalin ([3H]-DAMGO) (Thomasy et al 2007; Segal 1988; Hoffman et al 1990). Direct application of [3H]-DAMGO to various brain regions has been safely and effectively performed in several experiments with a dose range of $0.025 \mathrm{ug} / 0.5 \mathrm{ul}$ to 5ug/0.5ul, with most studies using a moderate dose of $0.5 \mathrm{ug} / 0.5 \mathrm{ul}$ (Bontempi and Sharp 1997; Przewlocka et al 1998; Zhang et al 1998; Will et al 2006). These studies point to the use of [3H]-DAMGO as a way to effectively manipulate patch striatal neurons and test the contribution of the patch compartment to spatial learning.

\section{Purpose of the Present Experinent}

The hypothesis of the present thesis was that [3H]-DAMGO injected directly into the dorsal striatum would impair spatial learning. The null hypothesis was that injections 
of [3H]-DAMGO into the dorsal striatum would have no effect on spatial learning. Spatial learning was tested using three different variations of the Morris Water Maze task.

\section{Experiment 1}

Before any behavioural tests were run, it was necessary to quantitatively analyze the effects of [3H]-DAMGO on the animals' behaviour. This was done because there have been no studies on the effects of [3H]-DAMGO delivered to the dorsal striatum beyond a study on its effects on feeding within the ventral striatum (Zhang and Kelley 2000). In studies performed on other brain regions, [3H]-DAMGO injections led to high fat consumption (Will 2006; Zhang and Kelley 2000) or circling locomotor responses following injection in the ventral pallidus (Hoffman et al 1991). Without initial testing of the general behavioural profile produced by dorsal striatum injections of [3H]-DAMGO, any significant results on spatial learning in the water maze could have been the result of behavioural abnormalities resulting from the administration of the drug rather than due to an effect on learning. General behavioural effects were tested through qualitative observation on an open field test of rats given [3H]-DAMGO injections.

\section{Experiment 2}

Once it was established that there were no adverse behavioural consequences of [3H]-DAMGO injections, various aspects of spatial learning were analyzed using the Morris water maze. In Experiment 2, daily injections of [3H]-DAMGO were delivered to the dorsal striatum to test whether animals with striatal patch neurons inhibited could 
learn the spatial location of a hidden platform. Improved latency to the platform within and across days provided an indication of spatial acquisition. Memory for the location of the platform on the first trial of each day was one measure of spatial retention. A final drug free probe test (with no platform present in the maze) was conducted on the fifth day to fully demonstrate retention and test any state-dependent learning of the location of the platform.

\section{Experiment 3}

In Experiment 3, the rats were pre-trained in the water maze without [3H]DAMGO injections over four days to a single hidden platform location. On the fifth day, rats were injected with the drug and the platform was moved to a new location.

Therefore, rats were trained to find the platform in this new location under the effect of drug. As there are both motoric and spatial aspects of a rat's ability to find the location of a hidden platform, the pretraining was used as a method to eliminate any motoric issues arising from the administration of [3H]-DAMGO. Therefore this test was thought to be more illustrative of the spatial consequences of [3H]-DAMGO delivery. The following day the rats were tested to see which platform location (the original or reversal) they preferred. The choice of platform location on the final day was a measure of pure spatial learning. The switching of locations was also a measure of competition between memories for two spatial locations. 


\section{Experiment 4}

Experiment 4 was designed to test more specific hypotheses concerning the role of the patch compartment in spatial learning; the passive or active extinction of spatial memories. Passive extinction is seen as the normal loss of memory over time and active extinction is seen as the loss of memory due to the interference from a new memory. First the animals were trained, drug-free, to find a hidden platform at a single location. On the second day the platform was positioned for the first trial in the same location as the previous day. The platform was then moved to another location for the remainder of the trials on that day. This process of the platform location remaining the same on trial 1 of each day as the previous day then changing to a new location for the remaining trials was repeated until the fourth day when [3H]-DAMGO injections were given before training. This was thought to give two measures of memory decay; passive and active. The passive component would be the retention of the platform location from trials $2-8$ as measured by latency to find the platform in that same location on trial 1 of the next day (or some other time delay). The active memory decay component would be measured as the latency to locate the platform on trial 2 after it had been moved from the location was found on trial 1. These measures were hoped to better elucidate the function of the patch in spatial processing. 


\section{Materials and Methods}

\section{Subjects}

Seventy (70) male Long Evans hooded rats were used. The animals were housed in a temperature controlled vivarium with a 12 hour light-dark cycle and had free access to food and water. All experiments were conducted in accordance with the guidelines of the Canadian Council on Animal Care and protocols approved by the Carleton University Animal Care Committee.

\section{Surgical Procedures}

All animals were implanted bilaterally under isoflurane anaesthesia with $10 \mathrm{~mm}$ long, 26 gauge cannulas at coordinates of +0.5 (anterior - posterior), $+/-2.5$ (lateral), -3.5 (vertical) from bregma. Two contralateral screws were inserted to the depth of the dura mater to establish a base for the cement. Dental cement was applied to the uncovered skull and layered to below the height that the cannulas protruded from the skull. Both cannulas were filled with stylets that were also cemented to the head cap until the time of injection. The animals were given $1 \mathrm{ml}$ of rectal acetaminophen for analgesia and also administered $1 \mathrm{ml}$ of the local anaesthetic Bupivacaine to the skin of the scalp. The animals were given a minimum of four days following surgery to recover. 


\section{Apparatus}

\section{Open field}

The open field test was run on a brightly lit $140 \mathrm{~cm}$ diameter white circular field with 6 objects equidistant to each other attached to the floor.

\section{Water Maze}

The Morris water maze was a white, circular, polypropylene pool $155 \mathrm{~cm}$ diameter, $60 \mathrm{~cm}$ height filled with water to $37.5 \mathrm{~cm}$ depth. The water temperature throughout behavioral testing was $21^{\circ} \mathrm{C}$. Non-toxic powdered paint was added to the water to make it opaque. A platform made of clear Plexiglas $14 \mathrm{~cm}$ in diameter was placed into the center of a designated quadrant of the pool and was submerged $2.0 \mathrm{~cm}$ below the water surface. The walls of the room had various visual cues on them, such as black dots, crosses and posters. The experimenter remained seated in the same position in the room throughout all testing trials. As well, a computer was located next to the experimenter thereby providing auditory cues due to the ultrasonic sound waves produced by the monitor. All movements were tracked and analyzed using the Smart Tracking System (San Diego Instruments, San Diego, CA).

\section{Procedures}

\section{Injection}

At the time of injection, $11 \mathrm{~mm}$ long, 32 gauge injectors were inserted into the cannulas after removal of the stylets. The injectors were $1 \mathrm{~mm}$ longer than the cannulas allowing the injector to protrude into the animal's brain $1 \mathrm{~mm}$ beyond the cannula. The 
[3H]-DAMGO or vehicle was delivered at a rate of $0.25 \mathrm{ul} /$ minute over two minutes and the injectors were left in place for three minutes following injection to allow full diffusion of the drug.

\section{Experiment 1. [3H]-DAMGO, Patch blockade, and qualitative behaviour}

Eleven animals were given one drug free session in the open field where they were placed individually into the open field and allowed to freely explore. The rats' behaviour was qualitatively observed for a half hour, focusing on motility, exploration and stereotyped behaviour (such as repetitive circling of the external wall). The rats were then allowed to rest overnight and given a second test under the influence of different [3H]-DAMGO doses. For this second test, animals were placed into the open field fifteen minutes after injection of a specific [3H]-DAMGO dose in saline $(0,0.05,0.5$ or $5 \mathrm{ug} / 0.5 \mathrm{ul}$ with an $\mathrm{n}=2,3,3$, or 3 rats respectively). Qualitative observations were recorded and comparisons between the two days were made.

\section{Experiment 2. [3H]-DAMGO, Patch blockade and the acquisition of learning}

Experiment 2 assessed the effect of [3H]-DAMGO injections into the dorsal striatum on spatial acquisition. Twenty-four animals were run in two groups of 12 separated in time by one week. All animals were trained for four days on this Morris water maze acquisition task. Each rat was given four trials per day with each trial beginning from a different, semi-randomly selected start point along the perimeter of the pool. For each trial, the rat was placed into the pool against the wall. The order of start points was randomly assigned each day. The rats were given 60 seconds to swim to the 
platform. Once they located and mounted the platform (or placed there by the experimenter if $60 \mathrm{~s}$ had elapsed), they were allowed to remain on the platform for 15 seconds before they were dried off with a towel and placed into a warm, dry cage. The training was spaced, so six animals at a time would each individually have a trial from the first starting position before all six would move to the next position, repeated over all four positions. The rats were given daily injections with a specific dose of [3H]DAMGO in saline $(0,0.05,0.5$, and $5 \mathrm{ug} / 0.50 \mathrm{ul}$ with $\mathrm{n}=6$ animals per group) delivered one hour before each day's training. On the fifth day, animals were given a drug-free probe test in which the platform was removed altogether and the rats were placed into the pool at a random start point. All animals were allowed to swim for 60 seconds. Acquisition data were analysed using a standard two-way repeated measures ANOVA (group as the between factor and daily latencies as the within subjects factor). Probe test data were analyzed with a two-way ANOVA.

\section{Experiment 3. [3H]-DAMGO, Patch Blockade, and Spatial Learning}

Experiment 3 was conducted to test the effect of [3H]-DAMGO injections on spatial reversal learning. Twenty-two rats, run in two groups of 11 and separated by one week, were run through the four day Morris water maze acquisition task without any drug treatment. The acquisition trials were run according to the procedures described in Experiment 2. On the fifth day, rats were given injections one hour prior to training with a specific dose of $[3 \mathrm{H}]$-DAMGO $(0,0.05,0.5,5 \mathrm{ug} / 0.50 \mathrm{ul}$ in groups of $\mathrm{n}=5,5,6$, and 6 respectively) then given a reversal task, where the position of the platform was changed from its location during the first four training days to the opposite quadrant. Animals 
were given 16 trials (run as they were in the acquisition phase) to learn the new location of the platform. On the sixth day the animals were given a drug-free probe test, run in the same manner as the probe test in experiment two, to assess how well the animals had learned the position of the platform. Data were examined using three-way repeated measures ANOVA.

\section{Experiment 4. [3H]-DAMGO, Patch blockade and the extinction of learning}

Experiment 4 was designed to determine, with more detail, the contribution of striatal patch neurons to spatial retention and acquisition. Twelve animals were given eight trials per day over three days in the water maze to a hidden platform location that was in the same location on the first trial as the last trial of the previous day then moved to a new location for the remaining seven trials. On the fourth day the rats were injected with a specific dose of [3H]-DAMGO in saline $(0$ and $0.05 \mathrm{ug} / 50 \mathrm{ul}$ with $\mathrm{n}=6$ animals per group) and then given the task as normal. Otherwise, the procedures matched the standard water maze procedures outlined in experiment two. Data were analysed using two way repeated measures ANOVA. 


\section{Results}

\section{Experiment 1}

The rats' behaviour on an open field was observed following injection of [3H]DAMGO into the dorsal striatum. The observations focused on motility (such as how easily they moved, how frequently they moved, any visible motor issues), exploration (sniffing new objects, travelling between objects), and stereotypies (repetitive nonpurposeful actions such as circling the walls, head rearing, circling on the spot). Qualitative observation found that 10 of the 12 rats were not visibly different in their behaviour or movement after [3H]-DAMGO injections. Two of the rats, one given a high dose $(5 \mathrm{ug} / 0.50 \mathrm{ul})$ and one given the medium dose $(0.5 \mathrm{ug} / 0.50 \mathrm{ul})$, sat rigidly in a single position for the initial 10 minutes in the case of the high dose and for the entire 30 minutes for the medium dose rat. It seems unlikely that this rigid posture was related to the $[3 \mathrm{H}]-\mathrm{DAMGO}$ dose to the striatum, as the medium dose rat saw a greater effect than the high dose, despite the high dose being more concentrated by a factor of ten. Overall the results of Experiment 1 were felt to be sufficient evidence that there was no adverse behavioural effects of the $[3 \mathrm{H}]-\mathrm{DAMGO}$ injections.

\section{Experiment 2}

Rats were given daily injections and trained on a standard four day, four trials per day water maze acquisition paradigm. The cannula placements for the animals of this experiment are represented in Figure 3. 
The daily average results are presented in Figure 4 (in all cases error bars represent standard error). A two way ANOVA revealed a main effect of day $(F(1,3)=$ 163.61; $\mathrm{p}=0.001)$, a main effect of group $(\mathrm{F}(3,19)=4.20 ; \mathrm{p}<0.05)$ and an interaction between day and group $(F(3,19)=3.88 ; p<0.05)$. Analysis of the results showed delivery of the low dose of [3H]-DAMGO $(0.05 \mathrm{ug} / 0.50 \mathrm{ul})$ resulted in an enhanced acquisition of the location of the platform compared to the control group. This group also plateaued at a lower latency to reach the platform compared to the control group. Delivery of the medium dose of [3H]-DAMGO ( $0.5 \mathrm{ug} / 0.50 \mathrm{ul})$ resulted in performance comparable to controls. The rats given the highest dose [3H]-DAMGO (5.0ug/0.50ul) were impaired in their acquisition of the task over the first three days compared to the controls but by the fourth day had achieved latency to the platform similar to the control group.

The results for the experiment were obtained in two separate iterations run a full week apart. To ensure that there was no time dependent effect, the data were separated into the two iterations for comparison. The results of the first and second iteration are presented in Figures $4 \mathrm{~b}$ and $4 \mathrm{c}$ respectively. This further analysis demonstrated that the controls, low dose and medium dose were not different between iterations. The high dose did show a delayed latency to the platform location on the second iteration.

To further analyse the rat's performance following [3H]-DAMGO injections, the distance that the rats swam was examined and is presented in Figure 5. The rats all swam approximately the same distance to reach the platform, except for the low dose animals which swam shorter distances to the platform, demonstrating an improved ability to swim directly to the platform. To examine possible motoric effects, the data were examined in 
terms of the average velocity that the animals swam at, shown in Figure 6. These results demonstrated that the high dose animals swam more slowly across all trials. This result indicates that the high dose animals were impaired motorically in their performance. The other groups performed similarly to the controls in the velocity of their swimming.

On the fifth day, a probe trial was run to determine how well the animals had learned the location of the platform. These probe data were broken down into 15 second intervals as shown in Figure 7. A two way ANOVA performed on these data revealed a significant interaction between the fifteen second interval and group $(F(3,18)=14.54 ; p=$ 0.001). Further analysis using the least significant difference (LSD) post-hoc test revealed a significant difference between the low dose and control during the first interval $(p<0.01)$. Analysis of the results showed the low dose group spent significantly more time in the position where the platform had been than any of the other groups during the first 15 second interval. In the subsequent intervals, these animals reduced their amount of time in this region so that they were equivalent to the controls by the second 15-second interval and spent less time in the target quadrant in each of the final two intervals. This pattern of reduced time spent in the platform location during the 60 second probe test was not observed in the other groups. The controls spent more time in the platform location over time and the medium and high dose spent a similar amount of time in the target quadrant during each of the successive time bins. 
Caption Figure 3

Figure 3. Representation of the cannula placements for the 24 Experiment 2 animals. Implants were bilateral, but are represented here only in a single hemisphere. 
Figure 3

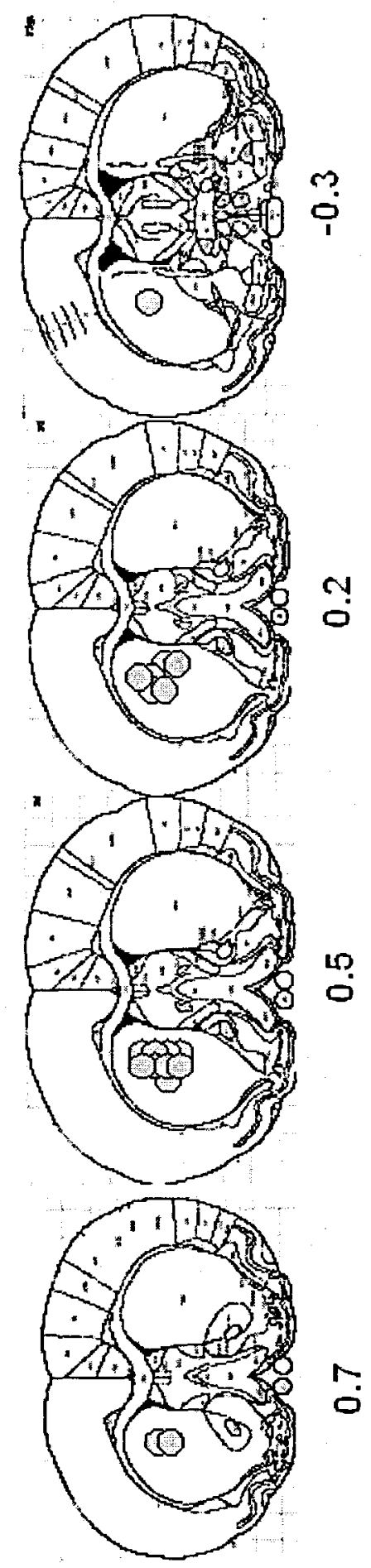




\section{Caption Figure 4}

Figure 4. The average daily latency in seconds to reach a hidden platform by the four groups. Animals were given four trials per day over four days. Error bars represent standard error of the mean. A: Overall results indicated an improved acquisition and overall performance for the low dose $(0.05 \mathrm{ug} / 0.50 \mathrm{ul})$ group compared to the control. The medium dose $(0.5 \mathrm{ug} / 0.50 \mathrm{ul})$ results indicated that this group was comparable to the control while the high dose $(5.0 \mathrm{ug} / 0.50 \mathrm{ul})$ seemed to have a decrease in acquisition compared to the control animals. B: Results for the first iteration. C: Results for the second iteration. Stars denote significance. 
Figure 4
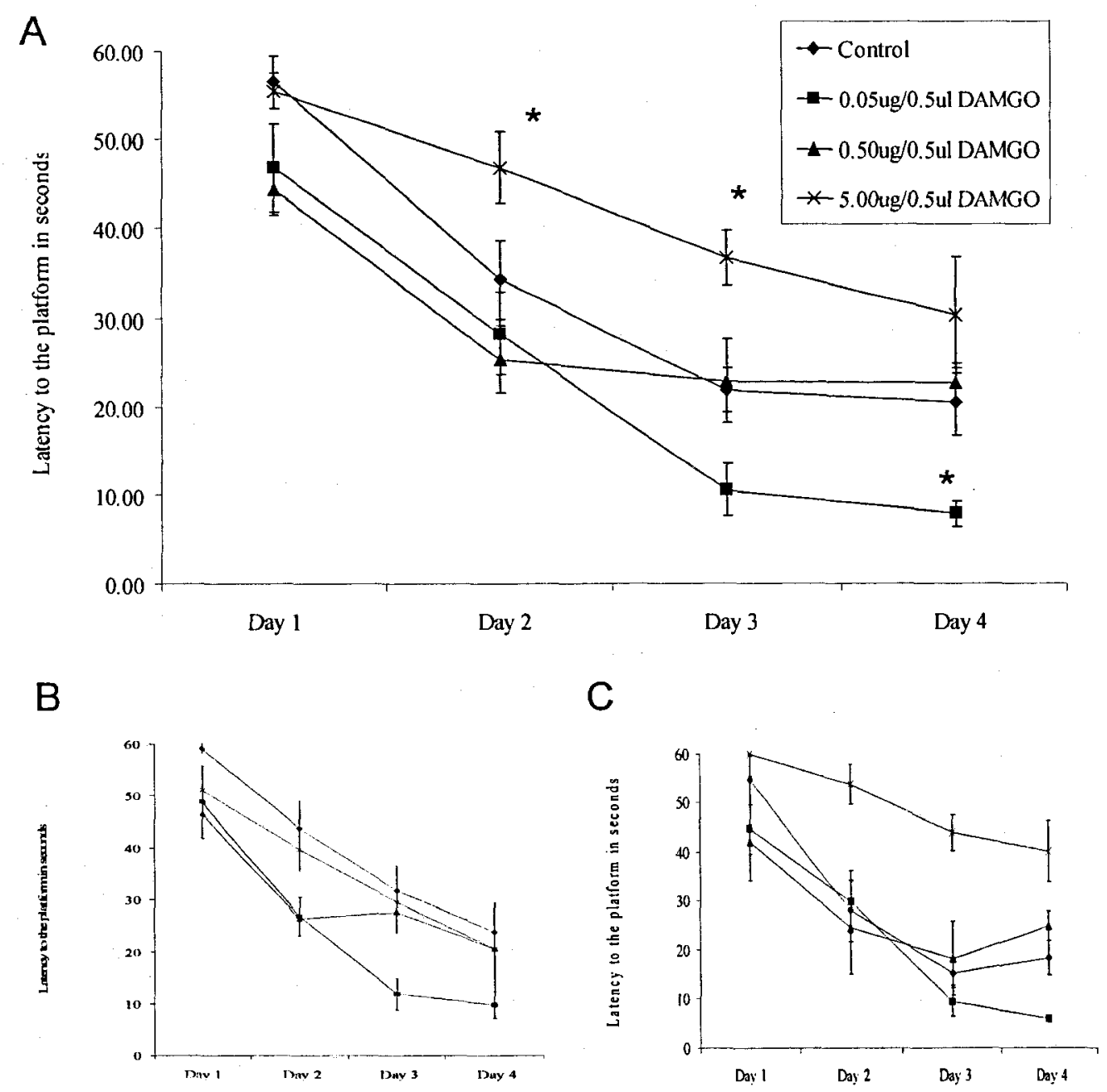


\section{Caption Figure 5}

Figure 5. The average daily distance swum in centimetres to reach a hidden platform by each of the 4 groups. Animals received four trials per day. Results demonstrated that the low dose $(0.05 \mathrm{ug} / 0.50 \mathrm{ul})$ group swam a shorter distance to the platform than any other group. The control $(0 \mathrm{ug} / 0.50 \mathrm{ul})$, medium $(0.50 \mathrm{ug} / 0.50 \mathrm{ul})$ and high dose (5.00ug/0.50ul) groups all showed similar performance in terms of distance swum to the platform. Stars denote significance. 
Figure 5

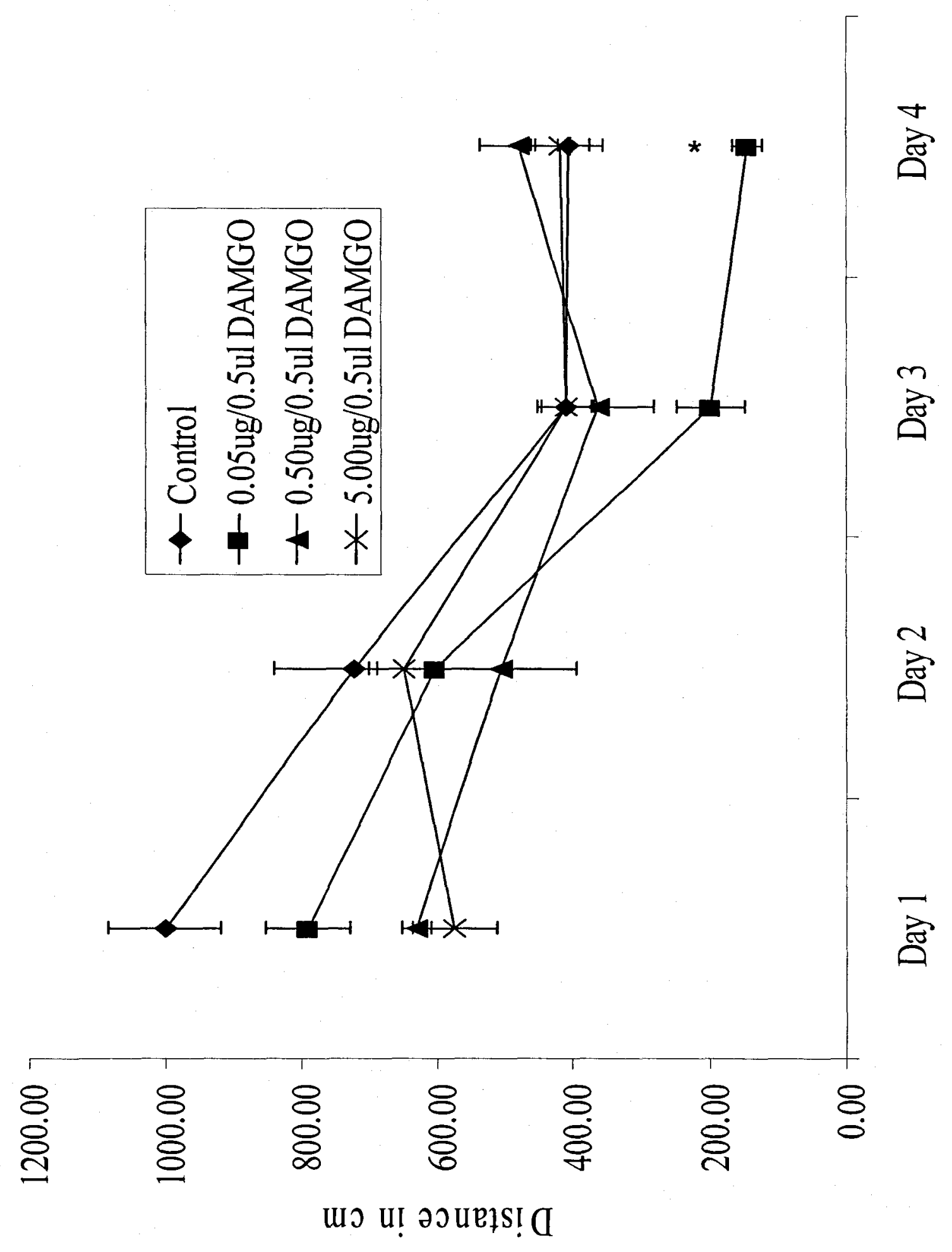


Caption Figure 6

Figure 6. The average daily swimming velocity in centimetres per second to reach a hidden platform by each of the 4 groups. Animals received four trials per day. Results demonstrated that the high dose $(5.00 \mathrm{ug} / 0.50 \mathrm{ul})$ animals swam significantly slower than any other group. The control (0ug/0.50ul), medium $(0.50 \mathrm{ug} / 0.50 \mathrm{ul})$ and low dose $(0.05 \mathrm{ug} / 0.50 \mathrm{ul})$ groups all swam to the platform at a similar speed. Stars denote significance. 
Figure 6

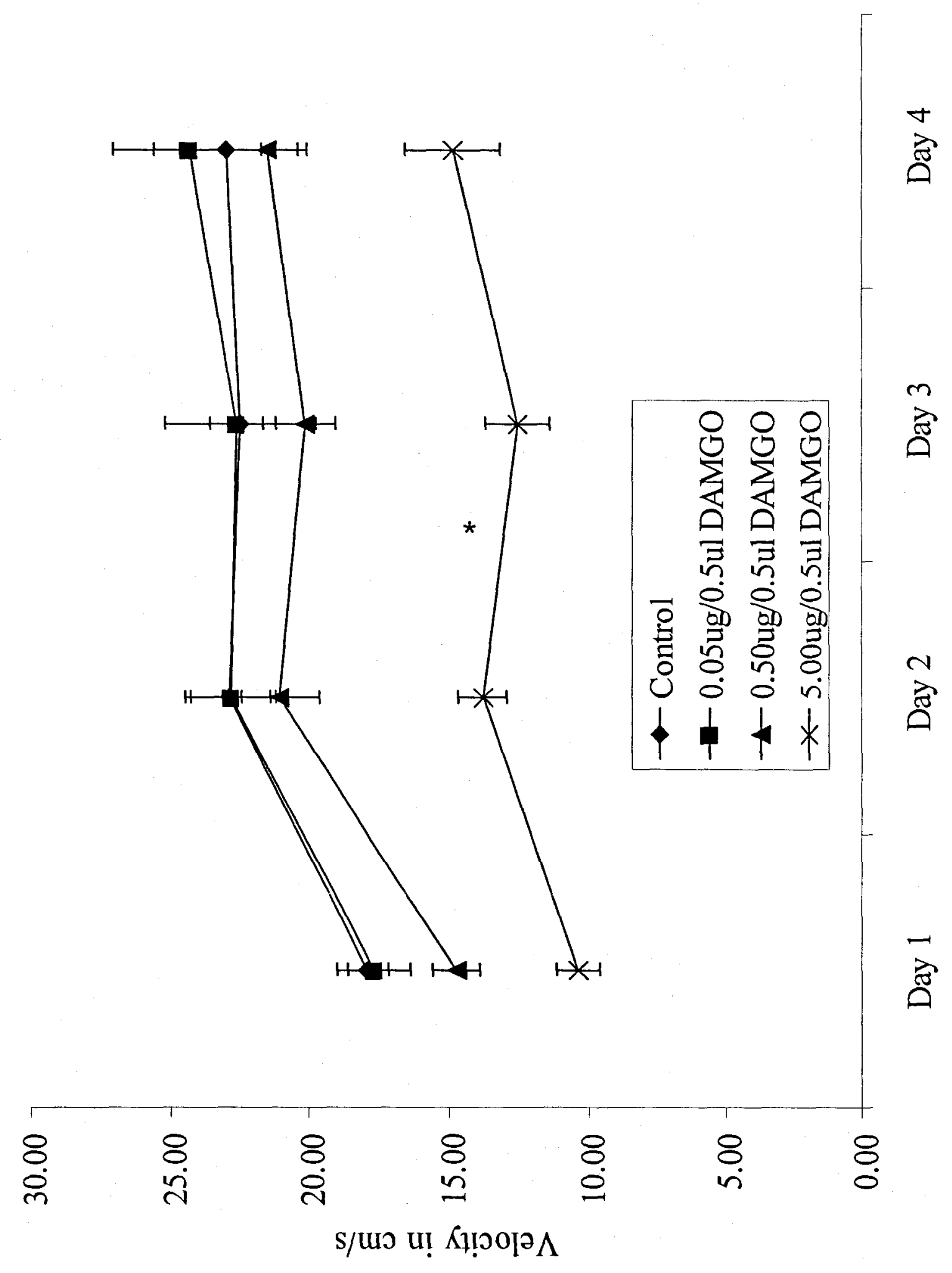




\section{Caption Figure 7}

Figure 7. Percent time spent in platform (target) quadrant per fifteen second

interval. Error bars represent standard error of the mean. The rats were given 60 seconds to swim in the water maze with the platform removed. The percent time spent in an area four times the diameter of the platform, in the location where the platform had been over the previous four days, was measured. The low dose group spent significantly more time in the region where the platform had been than any other group in the first fifteen second interval, but then reduced their time spent in this region over the following intervals. This pattern was not seen in the other groups. Stars denote significance. 
Figure 7
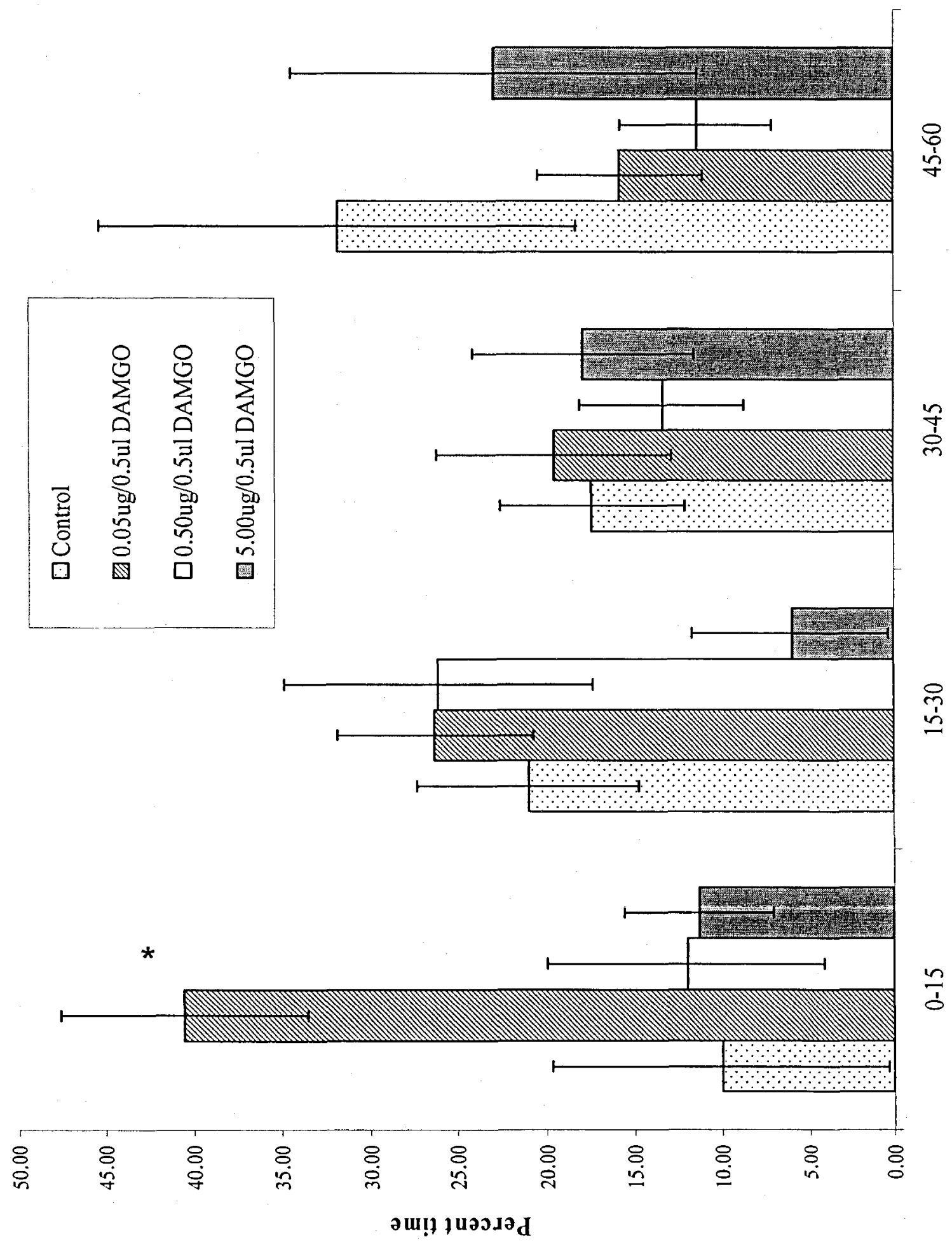


\section{Experiment 3}

Representative cannula placements for Experiment 3 are shown in Figure 8. Rats were given four days of drug-free training in the standard water maze acquisition task. On day 5, they were given injections of [3H]-DAMGO to the dorsal striatum and trained to a new platform location. On the sixth day, they were given a probe test to determine the strength of their spatial retention - either to the location associated with the initial learning or reversal learning. Results of the drug free acquisition are presented in Figure 9. As expected, the animals all learned the position of the platform at the same rate.

The results of the reversal day are presented in Figure 10. A two-way repeated measures ANOVA was run on the data for the reversal day. Analysis revealed a main effect of trial $(F(1,18)=15.26 ; p=0.001)$ indicating that all the animals learned the position of the platform over the 16 trials. There was no significant effect of group $(F(3,18)=1.13)$ nor an interaction between group and trial $(F(3,18)=0.54)$.

Analysis of the probe test with the data divided into fifteen second intervals presented in Figure 11. A three way ANOVA revealed a 3 way interaction between interval, platform location (initial or reversal) and dosage group $(F(3,18)=6.50 ; p<$ $0.01)$. The interval data revealed that the low dose group was spending as much time in the reversal location as the other groups during the first fifteen second interval but significantly less time in the initial platform position. However, over the subsequent intervals, the low dose group, while spending the same amount of time in the reversal location, significantly increased the amount of time spent in the initial platform location, spending much more time in this location than the other groups. 


\section{Caption Figure 8}

Figure 8. Representation of the cannula placements for the 22 Experiment 3 animals. Implants were bilateral, but are represented here only in a single hemisphere. 
Figure 8

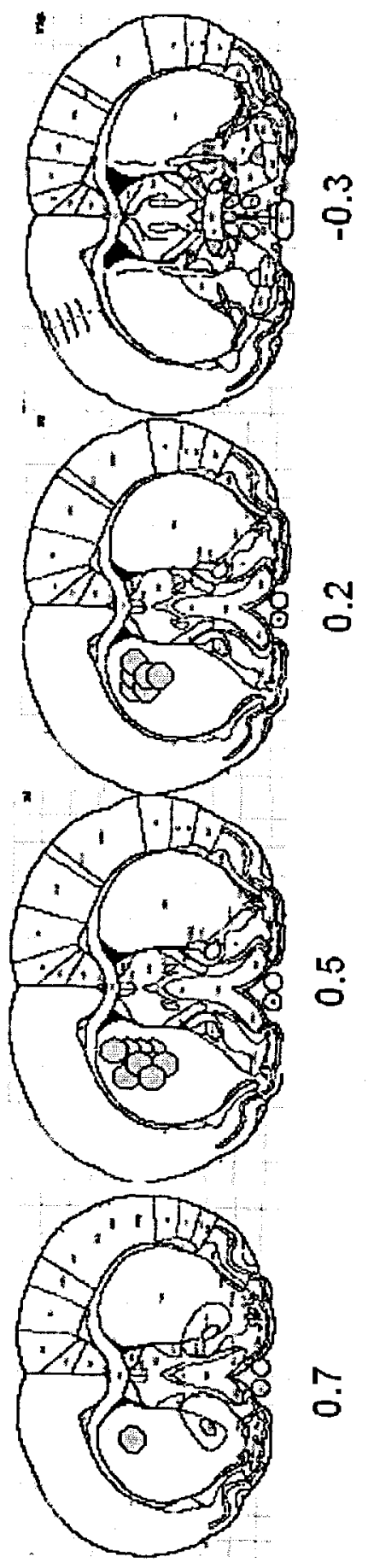




\section{Caption Figure 9}

Figure 9. The average daily latency in seconds to reach a hidden platform by [3H]-DAMGO dosage group with no treatment administered. Animals received four trials per day over four days. Error bars represent standard error of the mean. Results demonstrate no significant difference between groups. All groups decreased their latency to the platform to a plateau between ten and twenty seconds. 
Figure 9
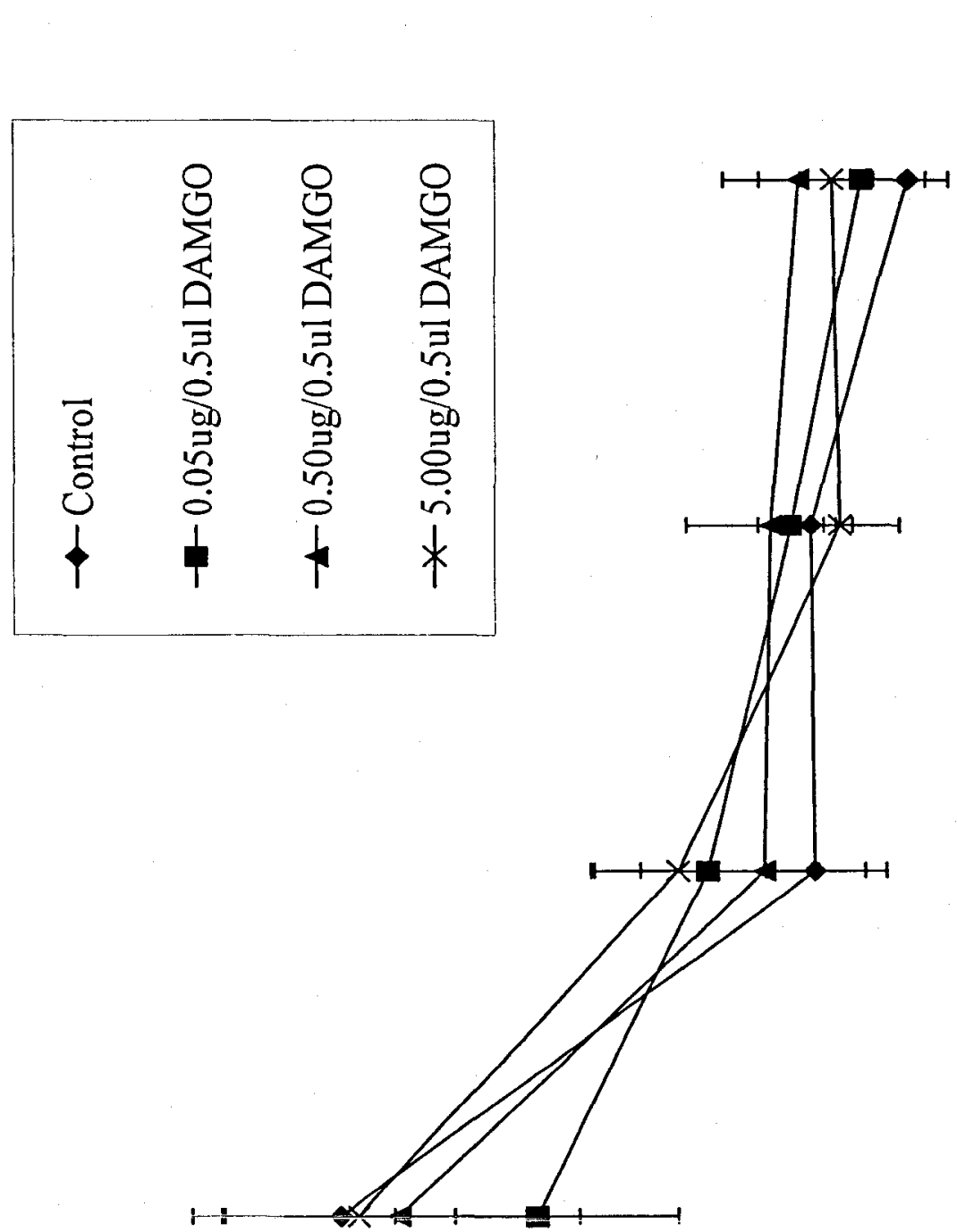

จ

m

ฉ

N

灾

己

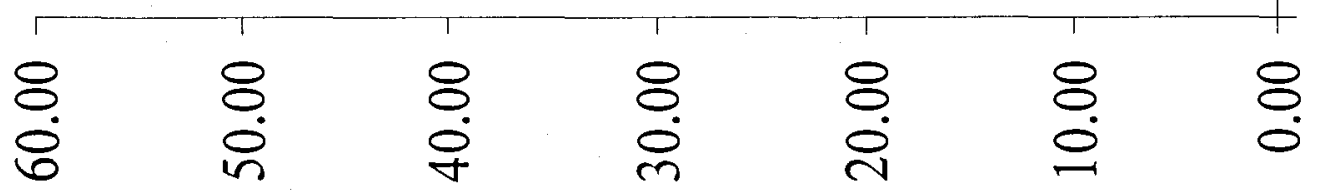

spuoวəs u! Kouə๋е T 
Caption Figure 10

Figure 10 . The average latency in seconds to reach a hidden platform by $[3 \mathrm{H}]-$ DAMGO dosage group by trial. Animals received 16 trials to a new platform location. All trials were given within an hour of delivery of the [3H]-DAMGO dosage. Error bars represent standard error of the mean. The results show overall performance for all groups was similar. 
Figure 10

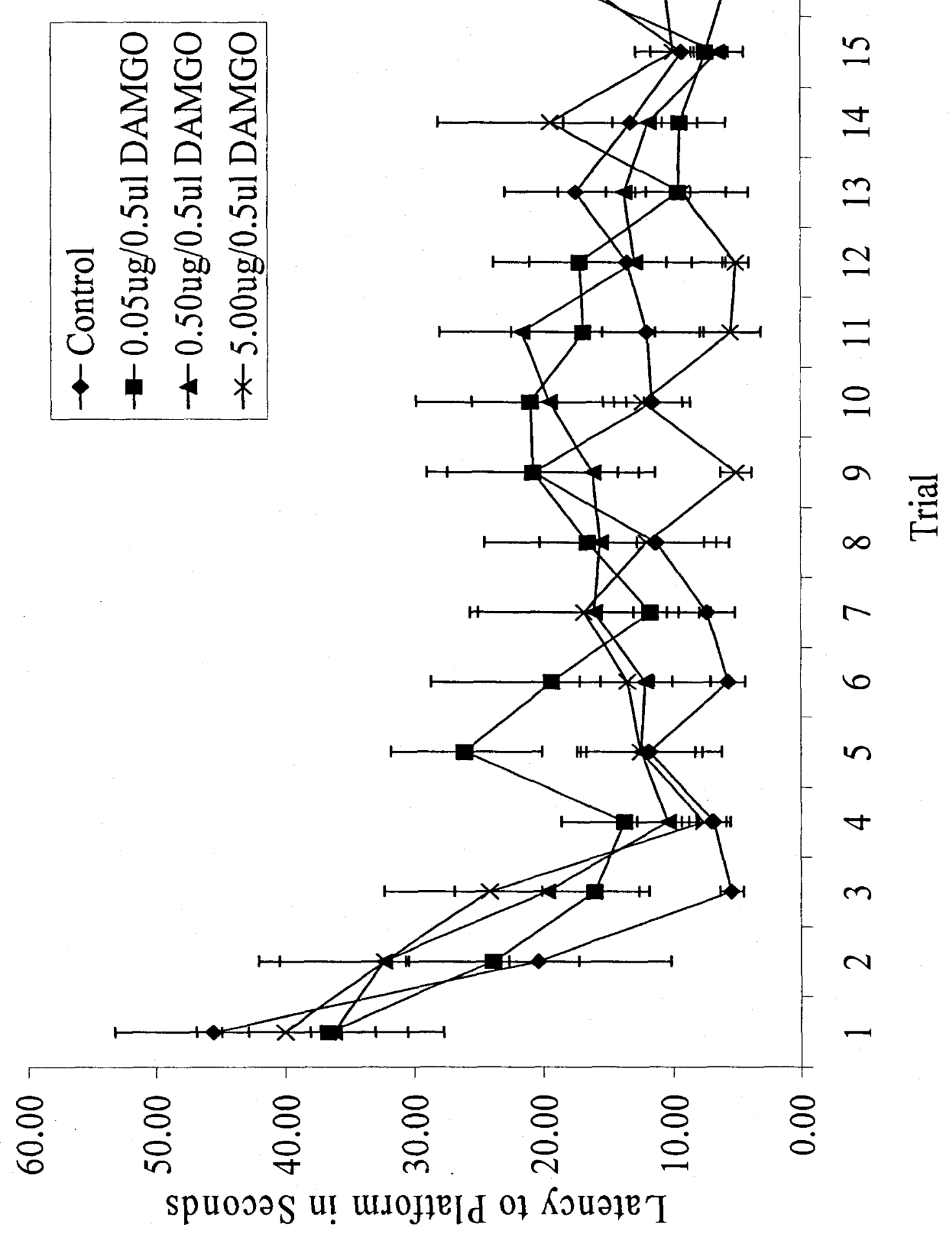




\section{Caption Figure 11}

Figure 11. The percent time spent in the two platform locations (initial and reversal) by [3H]-DAMGO dosage group by fifteen second interval. Error bars represent standard error of the mean. The rats were given 60 seconds to swim in the water maze with the platform removed. The percent time spent in an area four times the diameter of the platform was measured. Results indicated that all groups, except for the low dose (0.05ug/0.50ul), spent more time searching the reversal platform position. The low dose group spent the same amount of time in the reversal location as the other groups over all the time intervals but began with a low percent time spent in the initial platform position and gradually increased that time over the following intervals. A: The percent time spent in the reversal position by dosage group by fifteen second interval. B: The percent time spent in the initial position by dosage group by fifteen second interval. Stars denote significance. 
Figure 11

A

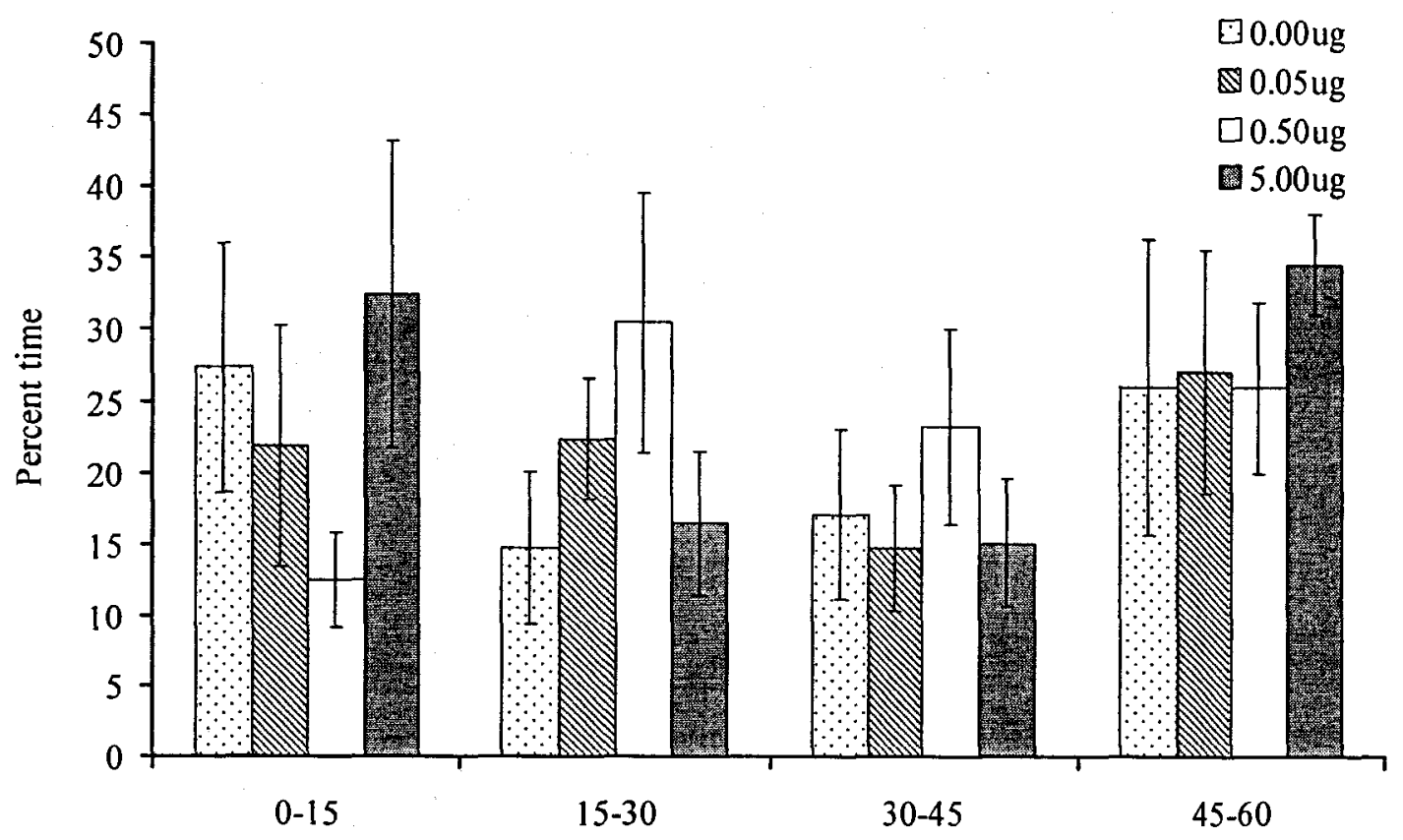

B

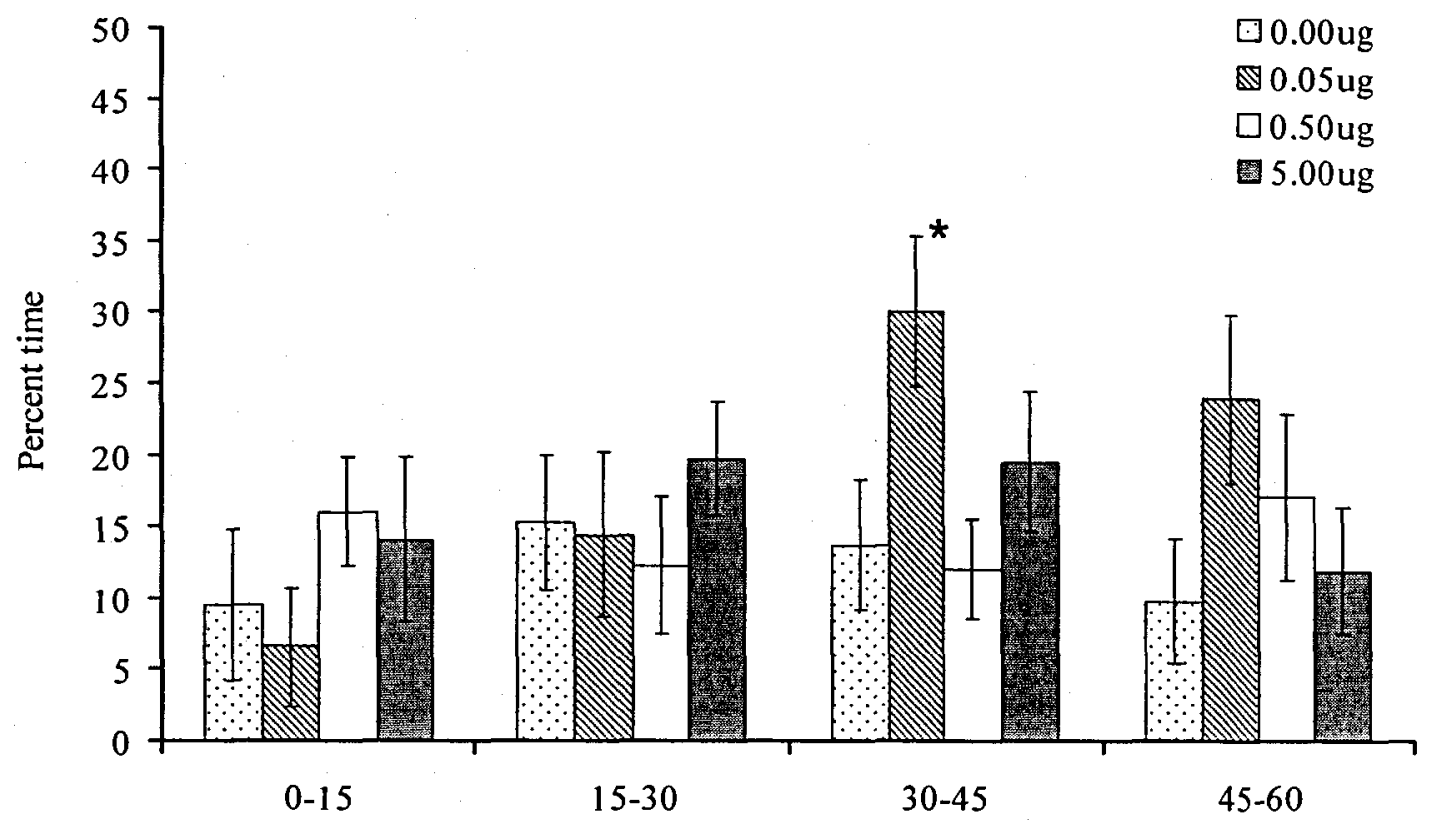




\section{Experiment 4}

Representative cannula placements are shown in Figure 12.

Animals were given three days of training in a platform-switching task. Eight trials were given per day to locate the hidden platform. The platform location was switched between the first and second trials of the second and third days. The platform location on trial 1 for each day was the same as the final platform position of the previous day. For trials $2-8$, the platform location was moved to different area of the water maze. On the fourth day, the rats were injected with [3H]-DAMGO $(0.05$ ug dose or saline) then trained with the platform remaining in the same location for trial 1 as the previous day then switched to a different location for trials $2-8$. On the fifth day the animals were given a single trial to the final platform position from the previous day.

Results for the drug-free acquisition are presented in Figure 13. As was expected, there was no significant difference between the groups in their acquisition of the task before any drug was delivered. The results for the fourth day are presented in Figure 14. As the only trials of interest on this day were the first three, a two-way, repeated measures ANOVA was performed only on the data from these trials. This revealed a 2way interaction between trial and group $(F(1,9)=19.73 ; \mathrm{p}<0.01)$. Analysis of these results showed the low dose $(0.05 \mathrm{ug})$ animals performed the task significantly more slowly than the controls on trial 1 then significantly better than the controls following platform relocation. Both groups performed similarly in locating the platform on the third trial.

The results for the fifth day are presented in Figure 15. Overall both groups performed similarly on the last trial of the fourth day, and although there was some 
indication that the low dose group was impaired in their ability to locate the platform on the first trial of the fifth day compared to controls, there was no significant difference between the groups $(\mathrm{t}(9)=4.26)$. 
Caption Figure 12

Figure 12. Representation of the cannula placements for the 12 Experiment 4 animals. Implants were bilateral, but are represented here only in a single hemisphere. 
Figure 12

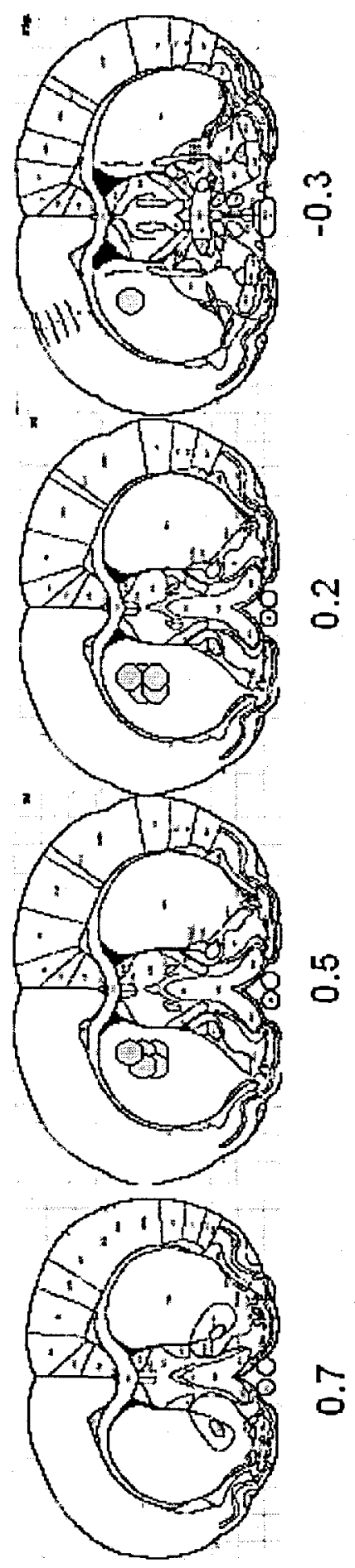


Caption Figure 13

Figure 13. The average daily latency in seconds to reach a hidden platform for Experiment 4. Animals received eight trials per day over three days. The platform position was relocated between the first and second trial on the second and third days. Error bars represent standard error of the mean. Results showed no significant difference in the acquisition of the platform position between the low dose $(0.05 \mathrm{ug} / 0.50 \mathrm{ul})$ group and the control. 
Figure 13

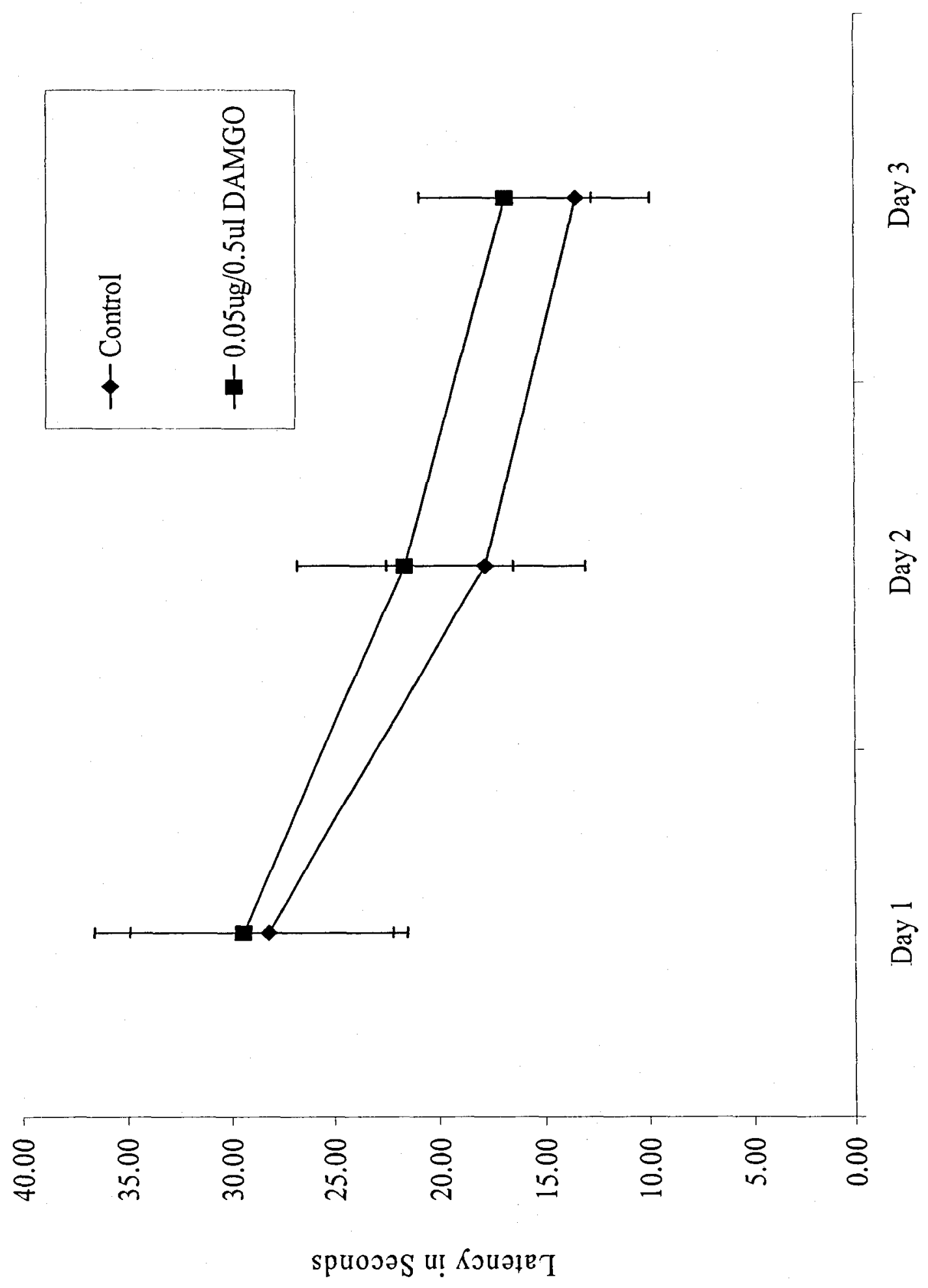




\section{Caption Figure 14}

Figure 14. The average latency in seconds to reach a hidden platform location by trial in a platform-switching task following [3H]-DAMGO or saline injection. Animals received eight trials over the day. All trials were given within an hour of delivery of the [3H]-DAMGO injection. The platform position was relocated between the first and second trial. Error bars represent standard error of the mean. Results revealed a significant difference between the low dose group and the control on both the first and second trials. On the first trial, the low dose group was significantly slower in locating the platform. On the second trial, the controls were significantly impaired in their ability to find the platform. There was no difference between the groups over the remaining trials. Stars denote significance. 
Latency ih Seconds

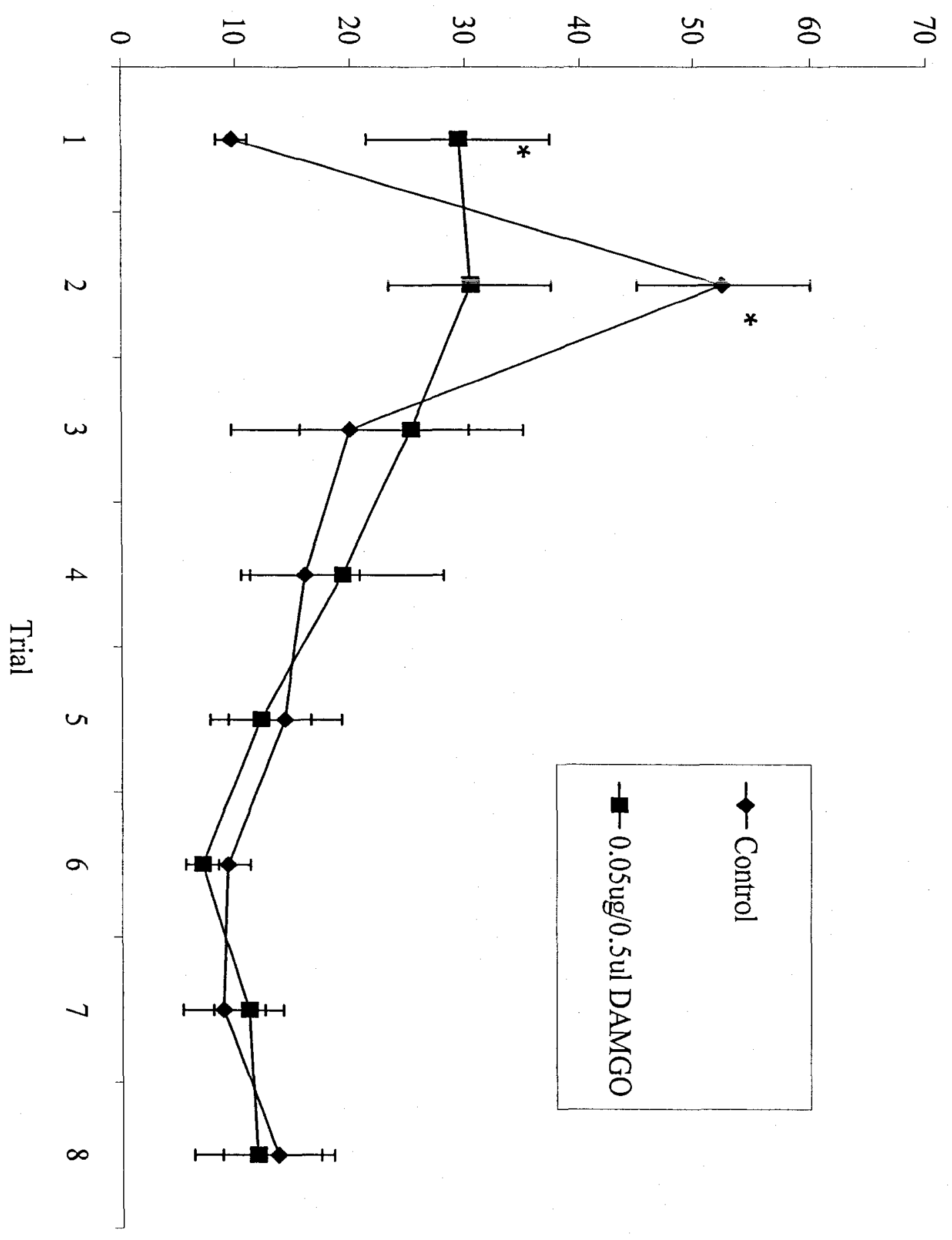

เ ว.มกถ์!

ऽS 
Caption Figure 15

Figure 15. The latency in seconds to reach a hidden platform on the final trial of day 4 compared to the first trial of day 5 . Animals had received eight trials over the fourth day, and a single trial on the fifth day, 24 hours following the previous trial. Error bars represent standard error of the mean. Results showed both groups performing similarly on the fourth day, and while there was the indication that the low dose group had a longer latency to the platform on the fifth day, there was no significant difference. 


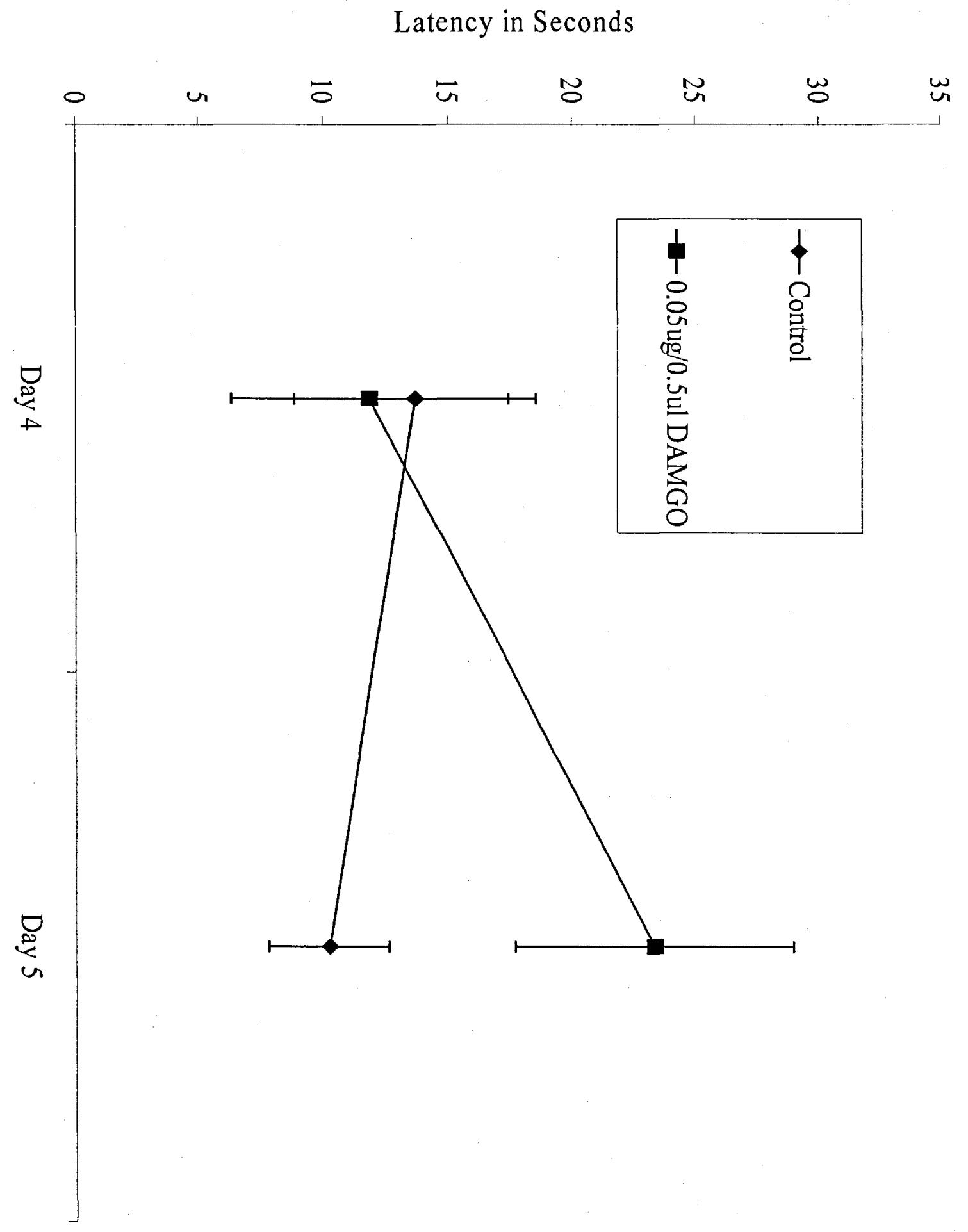

SI ว..กถ์!ป

$\angle S$ 


\section{Discussion}

The first part of the discussion consists of a summary and analysis of the results for each individual experiment reported in the thesis. The second part of the discussion serves as a general synthesis of the main findings from Experiments $2-4$ in relation to the function of the patch system in spatial learning and memory.

\section{Experiment 1}

Experiment 1 was carried out to determine the general behavioural profile following injections of different doses of [3H]-DAMGO into the dorsal striatum. Because the behavioural responses following [3H]-DAMGO injections into the dorsal striatum were unknown, it was imperative to examine this before performing any cognitive testing. Importantly, a previous study found that [3H]-DAMGO injections into the ventral pallidus, another region of the basal ganglia, led to circling locomotor responses (Hoffman et al 1991). This type of motor dysfunction, if found following [3H]-DAMGO injections into the dorsal striatum, might lead to impairments in swimming behaviour thereby invalidating the subsequent experiments. Therefore, a subset of animals were injected with different doses of [3H]-DAMGO (0.05 ug, $0.50 \mathrm{ug}$ and $5.00 \mathrm{ug}$ ) into the dorsal striatum and placed into an open field allowing for general behavioural observations. Qualitative analysis of the rats' behaviour revealed no major motoric dysfunction following injection of the 0.05 ug dose. Within the other [3H]DAMGO-injected rats, one medium and one high dose animal remained motionless 
following placement into the open field apparatus after drug injection. The 5.00 ug-dose animal was immobile for ten minutes and the 0.50 ug-dose animal remained immobile for duration of the test $(30 \mathrm{~min})$. Both animals showed normal locomotor and exploratory behaviour when they were returned to their cages.

In light of these behavioural observations, it appeared that the medium and high doses may have had some motoric effect. This could have been due to several factors; positioning of the cannulas, mechanical damage to the dorsal striatum (a region associated with motor function) produced by the injector, or diffusion of the drug to other motor regions possibly via the ventricles. Alternatively, the rigid posture seen could have been a fear response due to the injection procedure, coincidentally seen in the two higher dose animals but ultimately occurring independently from the [3H]-DAMGO injection. The cannula position did not seem to be a factor and mechanical damage could not be a main contributing factor as this would have been seen with all of the injections. One possibility is that the drug directly affected motor function mediated by the dorsal striatum or diffused into the ventricles and spread to other regions that mediate motor function. [3H]-DAMGO is an opioid and it is similar to morphine in that they are both mu-opioid agonists. Morphine is known to have rewarding effects, reduce hyperactivity and reduce operant responding in male rats (Craft et al 2006). If the higher doses of [3H]-DAMGO injections led to any of these side effects, it could potentially interfere with the motoric output of the animal. 


\section{Experiment 2}

Experiment 2 was designed to examine directly the role of the patch compartment of the dorsal striatum in spatial learning. To test the hypothesis that inhibition of the patch would impair spatial learning, daily injections of different doses of [3H]-DAMGO were used and rats were trained to find a hidden platform on a standard Morris water maze task. Daily [3H]-DAMGO injections did have consequences for the acquisition of the hidden platform task, though somewhat unpredicted. The high dose of [3H]DAMGO impaired the acquisition of the platform location compared to controls, while the low dose group showed an enhanced performance compared to controls. In the case of the high dose, this was consistent with the hypothesis that inhibition of the patch compartment of the dorsal striatum impaired spatial learning. In the case of the low dose, which showed improved performance compared to controls, this was inconsistent with the hypothesis. During the probe test, the high dose group never showed a search preference in the area associated with the platform while the low dose group initially showed a very strong preference for the spatial location which declined as time progressed. These findings are consistent with memory impairment and memory enhancement in the high and low doses, respectively.

In the first case, the high dose impairing acquisition, this could have been due to an effect on the animals' ability to perform the task or a true effect on spatial learning. In light of the results of the first experiment, the impairment in acquisition seemed to be further evidence for a motoric issue resulting from the higher dose. That there could be a motoric deficit is also indicated at the results from the swimming velocities, where the 
high dose animals swam significantly slower than any of the other groups. The nature of this performance deficit was further addressed in Experiment 3.

In the second case, with the low dose group showing an apparent memory enhancement, this could have been due to a true effect on cognitive processes (described in more detail in the general discussion below) or some other metric. The control animals did appear to have longer than typical latencies to locate the hidden platform, which could be seen as a behavioural abnormality. This would, as a consequence, skew the results and confound the interpretation that the low [3H]-DAMGO dose produced an enhancement in learning. However, the animals were run in two separate groups with a gap of a week between groups. This division into two groups with a gap between them meant that essentially the data were replicated between the two groups strengthening the hypothesis that the low dose animals displayed an improvement in their performance over the controls.

One reason for the somewhat longer latencies displayed by the control group could be the effects of handling during the injection procedure which was delivered within an hour of testing. The injection procedure could be viewed as stressful for the animals, as it involved being restrained for ten minutes, with their heads handled extensively during that time. That stress has a deleterious effect of on spatial learning in male rats has been documented (McLay et al 1998; Mizoguchi et al 2000) and, more specifically, restraint as a stressor has been demonstrated to cause impairments to spatial memory (Luine et al 1994).

The improved performance of the low dose group in Experiment 2 could have been for a variety of reasons, and it was unclear whether this improvement was due to a 
motoric effect or a cognitive effect. The improved performance was unlikely to be a motoric effect as not only were latencies lower but also distance to swim to the platform was lower in the low dose group compared to controls. As another, noncognitive influence on the enhanced performance, it could be postulated that there was some reward effect from delivery of the low dose of [3H]-DAMGO that was causing an improvement in the performance essentially enhancing the animals' desire to complete the task. As discussed previously, morphine has a similar effect to [3H]-DAMGO on the mu-opioid receptor. Morphine has been demonstrated to lead to positive reinforcement in tasks in rats (Zernig et al 2002). If this effect is extrapolated to [3H]-DAMGO it could help to understand the enhanced performance of the low dose rats. The reward effect may have been offset in the higher dose animals by the motoric complications.

The day five probe test data showed that the high dose animals spent less time in the target quadrant than the other groups and indicated that these animals were impaired in their performance compared to controls. The low dose group spent the most time in the target quadrant. To clarify this result, the data were broken down into fifteen second intervals. This analysis indicated that the low dose group spent significantly more of their time in the target quadrant during the first fifteen seconds than the other groups. The low dose group then gradually spent less time in the target quadrant over each of the remaining intervals. The controls and 2 higher dose groups spent less overall time in the target quadrant and did not vary much from interval to interval. During the probe test, the platform is not present, and consequently, an animal displaying an effective search strategy would search in the platform region and finding no platform, move on to search other regions of the pool, returning less frequently. The findings during the probe test 
indicated that this may be occurring with the rats in Experiment 2 given the low dose of [3H]-DAMGO. These animals, in spending most of their time in the target quadrant during the initial fifteen seconds, were clearly demonstrating good recall of the platform location, but in the following intervals they dramatically reduced the amount of time spent there. This reduction in time seems to indicate that the animals have realized there was no platform present in that location and were using an improved search strategy to attempt to find an alternate platform location. The increase in time spent in the target location over the 60 -s probe test by the control animals was the reverse of this strategy. It appeared as though the control animals required more time to locate the target zone and then redundantly persisted in swimming in that zone for the remainder of the time. This demonstrates that the control animals had a good recall of the location but were not using a flexible search strategy once it was apparent that there was no platform present.

\section{Experiment 3}

To minimize the contribution of any motoric or behavioural confounds that might have resulted from the $[3 \mathrm{H}]$-DAMGO injections and be responsible for the findings of Experiment 2, animals in Experiment 3 were pretrained on the task before [3H]-DAMGO injections. The main goal of Experiment 3 was to inhibit the patch in the dorsal striatum and measure the strength of spatial responses directed toward spatial locations in the water maze acquired under drug-free states or under conditions of opioid-mediated inhibition.

To achieve these goals, rats were trained over 4 days to swim to a hidden platform at a fixed location. On day 5, [3H]-DAMGO injections were made into the dorsal 
striatum after which the rats were given 16 trials to learn to swim to the hidden platform at a new location. Testing was done under drug-free conditions in the absence of the platform with a probe trial the following day where the rats could show a preference for the original or the reversed location.

There were no differences between groups in their ability to learn the new location of the platform under the influence of [3H]-DAMGO. This result is different from the results of Experiment 2 where the highest and lowest doses of [3H]-DAMGO affected the acquisition of the platform position. This change in ability to acquire the location of the platform under the influence of the drug between Experiments 2 and 3 is likely due to the pretraining. The effect of pretraining to alleviate motoric difficulties has been demonstrated in animals where inhibition of LTP in the hippocampus was caused by NMDA inhibitors (Saucier and Cain 1995; Bannerman 1995). Pretraining allows the animal to establish the procedural memory for the task before the learning process occurs. If an animal's learning is disrupted following pretraining, the impairment can be ascribed to deficits in cognitive processes rather than through any associated motor deficits caused by the treatment. This was seen in the change in results from Experiment 2 to 3, where the high dose rats performed poorly in Experiement 2 and similarly to controls in Experiment 4. It suggests that the pretraining in Experiment 3 alleviate a motor deficit produced by the high dose DAMGO injection.

Twenty-four hours after the injection, the platform was removed in order to test which region the rats spent most of their time. In this case, the null hypothesis, given no effect of drug treatment, was that the rats would spend more time in the reversal platform position as the full day of training would cause a retrograde interference on the retention 
of the initial platform position. This was the case for all the groups with the exception of the low dose animals, which spent the same amount of time in both regions. This could be seen as either an impairment in the ability to learn the reversal position due to the [3H]-DAMGO delivery or as an improved memory for the initial platform position.

To further understand this effect, the probe test data were broken down into fifteen second intervals. In this analysis it became clear that the low dose group, although they spent about the same time in the reversal location as the control, spent less time than the control in the initial location during the first fifteen second interval. In the next three time intervals, the low dose group increased their amount of time spent in the initial platform location dramatically. This indicated that it was not necessarily an impairment in the rats ability to learn the new platform location, but may instead have been the rats displaying an improved search strategy, first searching in the reversal day location and then searching in the location where the platform was on the initial days. The other animals could be seen as redundantly searching in the location that they learned most recently, despite the absence of the platform, a behaviour similar to the performance in Experiment 2.

\section{Experiment 4}

Experiment 4 was designed to clarify the nature of the improved performance of the low dose group by pretraining the rats in a platform switching task for three days before [3H]-DAMGO injection. On the day of the injection, the platform was maintained in the previous day's position for the first trial, but for the following trials, the platform position was moved to a new location to test for active memory interference. The rats 
were then trained to the new position and given a full day delay to test passive memory extinction.

On the first trial following injection, the control group showed lower latencies to reach the platform, located in the previous day's location, than the low dose group. It was somewhat difficult to reconcile why the controls outperformed the low dose group. The difference in performance could be a result of the switching task being learned as a single unit (the platform will be in one location and then switched on the next run is seen as a single unit of learning). It could also be an anomaly in that the controls and low dose groups in Experiment 4 showed the same pattern on the previous day with no injection. A larger $\mathrm{n}$ could help in the understanding of this result.

On the second trial, when the platform was in a new location, the group injected with the low dose of $[3 \mathrm{H}]$-DAMGO showed significantly lower latencies than the controls to find the platform in the new location. On the third trial, with the platform in the same location as trial 2 , the drug and control groups performed similarly. On the second trial, the rats had only the previous day's platform position in memory, not conflicting with any new position. That the low dose group showed lower latencies than the control group on the second trial but not the third is an indication that the trial 2 performance was not due to an active extinction or inhibition effect, as the third trial is more accurately a test of active memory; where the animals have two conflicting platform placements in memory and must choose between them.

On the final day, the rats were tested on their ability to locate the platform in the previous day's position, the location learned under the effects of [3H]-DAMGO. The low dose group was not significantly impaired in their ability to locate the platform 
compared to controls nor was there any improvement in performance. This lack of any drug effect on the final day could be related to the task learned in the experiment. Experiment 4 requires the learning of several platform locations over the four days and potentially also learning the switching task. That the low dose animals improved their ability to learn the location of the switched platform, but showed no difference in their ability to locate the platform after a delay suggests that the task should be modified to account for the possibility that the animals are learning the switching task as a single unit. The animals may be showing an improved ability to learn a search strategy which is not being tested in this latency task. If a second trial had been given on the fifth day with the platform switched it might have better tested for search strategy (to be discussed in more detail in the General Discussion).

\section{General Discussion}

The proposed hypothesis of this thesis was that DAMGO injection into the dorsal striatum would impair spatial learning. This hypothesis was tested, but not supported by the data. However, the null hypothesis was not supported either. Although the performance of the higher dose animals seemed to validate the hypothesis, analysis of their movement revealed that there was a motoric impairment. That a motoric impairment contributed to the water maze deficit in the high dose group was confirmed in Experiment 3 where pretraining alleviated the motoric issue leading to performance in this group that was comparable to controls. The low dose animals, however, demonstrated an improved performance over the controls in both the acquisition and retention of the task. This performance enhancement did not appear to be motoric, both 
through qualitative analysis and in terms of the results of Experiment 3 in which pretraining did not alter the enhanced performance over controls. Experiment 4 used exclusively the low dose group, which continued to demonstrate an improved ability to locate the platform once moved, whether through improved search strategy or by better retention of the platform switching task.

Although the hypothesis regarding [3H]-DAMGO causing inhibition of the patch leading to spatial deficit was not supported, there was a clear effect of the low dose of [3H]-DAMGO. This effect stems from one of two possibilities: either the [3H]-DAMGO is working according to expectations but the role of the patch is not what was expected or that [3H]-DAMGO is not working according to expectations, whether inefficiently, or in reverse of expectations.

\section{Alternate Explanation 1}

The first possible alternate explanation is that [3H]-DAMGO functions according to expectations by inhibiting the patch cells of the dorsal striatum. However, based on the results of the four experiments presented here, it would seem that if this is the case, the patch component of the dorsal striatum is not operating according to the hypothesized function. If this explanation is correct, there are several potential reasons as to why blockade of the patch led to an apparent improved performance on the tasks. The question of whether [3H]-DAMGO is working to inhibit the patch cells is testable and will be addressed below.

One potential way to consider the results of these experiments is to consider the

patch neurons of the dorsal striatum as a spatial memory system working in parallel to the 
hippocampus as was previously proposed by Devan and White (1999). In this explanation these two brain regions may be for different aspects of spatial memory or may be wholly redundant. The blockade of the patch may work to relieve the competition between the hippocampus and the patch cells of the dorsal striatum, resulting in improved hippocampal spatial information processing capacities. This would explain the improved latency of the animals in all cases, as well as the retention of the location in the probe trials. Running a comparison group with the fimbria-fornix severed but given pretraining, or possibly with asymmetrical lesions to the fimbria-fornix and the hippocampus as done by Devan and White (1999) may help to clarify this hypothesis.

A second potential explanation for the behaviour of the low dose group is seen by looking at the patch neurons of the dorsal striatum as the component of a spatial memory system responsible for the normal decay or extinction of memory. Memory decay is a normal and necessary function, ensuring that unneeded information is not retained by the brain. The majority of information received by the central nervous system is unnecessary and retention could cause impairment in the retention of, or attention paid to, critical information. In this case, the spatial memory would be encoded in the hippocampus and then pass through the patch cells, where the memory would be lost, or would be sent to higher processing regions. By this explanation, [3H]-DAMGO blockade of the dorsal striatum would impair this normal pathway resulting in the impairment of memory extinction. The low dose animals would then see an apparent improvement in performance because of the loss of memory decay. This explanation would suit the results of experiments 2 and 3 very well, with the improved latencies to the platform, as 
well as the retention of the location in the probe trials being due to the position of the platform being held in memory longer.

However, this explanation does not hold up as well in terms of the results of the fourth experiment. This experiment was set up to examine two potential aspects of memory decay, active and passive. Active extinction would be seen in the third trial of the fourth day, where the location of the platform had been switched in the previous trial, and as a result there are two locations competing for memory. Blockade of a postulated extinction system would lead to an increased performance over control on this trial. This was not the case. Passive memory was tested in this experiment with a 24 hour delay between first learning the location of the final platform under the influence of drug and a test for ability to find that platform location. With a blockade of a postulated passive extinction system the low dose animals should see an improvement in their ability to retain the location of the platform over the controls. This was also not seen in the results of Experiment 4. However, the experiment is a platform switching task, where, although the animals are to learn the location of the platform, the animals should also learn that the platform location is switched on the second trial of each day. Considering the data this way, the animals may be learning the task as a unit. As a result, the low dose animals may be performing poorly on the first trial of each day because they are expecting a switch of location, or just out of some complication due to the memory being of a unit of several trials.

In the case of the active memory task, this experiment could have been adjusted by switching the whole task during the injection day. As a result, the animals, having learned the platform switching paradigm, would have to learn a new paradigm which 
would conflict with their memory of the task. Animals with their active memory decay impaired would effectively remember both paradigms which could then be tested for. Passive memory would also be better tested for by testing for the full switched platform task. If there was a second trial on the final day after the 24 hour delay, this would test the animal's ability to recall the task as a unit.

\section{Alternate Explanation 2}

The second possible explanation is that [3H]-DAMGO is not working according to expectations. This could happen if the inhibition caused by [3H]-DAMGO was working to disinhibit dopamine neurons leading to an overall sensitization of the patch region of the dorsal striatum. If the hypothesis is that the patch is involved in spatial learning, this disinhibition would explain the improved performance of the [3H]DAMGO treated animals, although the precise nature of that improvement would still not be clear. Another possible way that [3H]-DAMGO could be failing to work according to expectations is if the mu-opioid receptors are not as predominant, or as significant as was believed, or that the $[3 \mathrm{H}]-\mathrm{DAMGO}$ is penetrating other brain regions through the ventricles, and causing effects there. If this were the case the reasons for the effects of [3H]-DAMGO would not be clear. The question of what precisely is occurring with the injections of [3H]-DAMGO could be further clarified with imaging studies to view the penetration of the drug, and the resulting neuronal activity caused by it. If [3H]-DAMGO was causing a disinhibition of the patch region, it would add weight to the hypothesis that the dorsal striatum is a region playing a role in spatial learning, although this role is not clear. 
Regardless of which alternate explanation proves true, it is important to discuss the question of the nature of the improvements in the acquisition and retention of the tasks seen with the low dose [3H]-DAMGO groups. Although it was hypothesised that the patch was involved in spatial memory, breaking down the probe trials into 15 second intervals leads to a possible different interpretation. The animals injected with [3H]DAMGO when viewed in terms of overall performance do seem to be demonstrating a memory improvement. However, when the results were broken down into fifteen second intervals, the low dose animals appeared to be demonstrating an improvement in search strategy. In Experiment 2, the low dose animals spent significantly more time in the area where the platform had been during the first fifteen second interval than any of the other groups, but this time decreased significantly over the successive intervals. In Experiment 3 , the low dose animals spent the first fifteen second interval primarily in the reversal platform position, with very little time spent in the initial platform position. They then increased dramatically the amount of time spent exploring the initial position over the following intervals. In both cases, the result points to an improvement in search strategy. In Experiment 2 for example, an animal with an improved search strategy would spend the initial portion of the probe trial searching within the location where the platform had been, but then with the discovery that the platform was not present, the animal would spend far less time in this region, focusing on other potential areas where the platform could be. In Experiment 3, the animal with an improved search strategy would go initially to the reversal platform position, but finding it not present, would next try the location where it had been previously. The improved search strategy hypothesis is strengthened by the results of the second trial on the injection day of Experiment 4 . In this trial, the 
platform had been switched and the new position was not known. The animals, however, have experienced this switch three times previously and so should have some concept that there is a platform present in the pool. The low dose [3H]-DAMGO group on the second trial of the injection day performed significantly better than the controls at finding the new platform location, a result which points to an improved search strategy.

This improved search strategy could point to a function of the patch cells, or an uncovered function of the hippocampus depending on which hypothesised function of [3H]-DAMGO proves to be true. It is also possible that this improvement in search strategy could be a direct effect of improved memory retention. Improved memory retention could allow an improvement in search strategy. The improvement in search strategy also does not rule out the hypothesis that the patch cells are responsible for passive extinction. The ability of the low dose animals to better locate the new platform location could be related to their ability to remember all the previous platform locations, or simply to remember that there were previous platform locations, thus improving their ability to find the new location. 


\section{References}

Ahlander, M., Misane, I., Schott, P.A., Ogren, S.O. (1999). A behavioural analysis of the spatial learning deficit induced by the NMDA receptor antagonist MK-801 (dizocilpine) in the rat, Neuropsychopharmacology, 3, 414-26.

Bannerman, D.M., Good, M.A., Butcher, S.P., Ramsay, M., Morris, R.G. (1995). Distinct components of spatial learning revealed by prior training and NMDA receptor blockade, Nature, 378(6553), 182-6.

Bontempi, B., Sharp, F.R. (1997). Systemic morphine-induced Fos protein in the rat striatum and nucleus accumbens is regulated by mu opioid receptors in the substantia nigra and ventral tegmental area, Journal of Neuroscience, 17(21), 8596-612.

Brown, L.L., Schneider, J.S., Lidsky, T. (1997). Sensory and cognitive functions of the basal ganglia. Current Opinion in Neurobiology, 7, 157-163.

Cain, D.P., Saucier, D., Boon, F. (1997). Testing hypotheses of spatial learning: the role of NMDA receptors and NMDA-mediated long-term potentiation, Behavioural Brain Research, 84(1-2), 179-93

Chang, Q., and Gold, P.E. (2003). Switching Memory Systems during Learning: Changes in Patterns of Brain Acetylcholine Release in the Hippocampus and Striatum in Rats, The Journal of Neuroscience, 23(7), 3001

Conn, P.M. (2003). Neuroscience in Medicine $2^{\text {nd }}$ Ed. New Jersey: Humana Press.

Craft, R.M., Clark, J.L., Hart, S.P., Pinckney, M.K. (2006). Sex differences in locomotor effects of morphine in the rat, Pharmacology Biochemistry and Behaviour, 85(4), $850-8$.

D'Hooge, R., De Deyn, P.P. (2001). Applications of the Morris water maze in the study of learning and memory, Brain Research Reviews, 36(1), 60-90.

Dash, P.K., Hebert, A.E., Runyan, J.D. (2004). A unified theory for systems and cellular memory consolidation, Brain Research Reviews, 45, 30-37

Desban, M., Kemel, M. L., Glowinski, J., Gauchy, C. (1993). Spatial organization of patch and matrix compartments in the rat striatum, Neuroscience, 57, 661-671.

Devan, B.D., Goad, E.H., Petri, H.L. (1996). Dissociation of hippocampal and striatal contributions to spatial navigation in the water maze, Neurobiology of Learning and Memory, 66, 305-323. 
Devan, B.D., and White, N.M. (1999) Parallel Information Processing in the Dorsal Striatum: Relation to Hippocampal Function, The Journal of Neuroscience, 19(7), 2789-2798

Donoghue, J. P., and Herkenham, M. (1986). Neostriatal projections from individual cortical fields conform to histochemically distinct striatal compartments in the rat, Brain Research, 365, 397-403.

Ekstrom, A., Kahana, M., Caplan, J., Fields, T., Isham, E., Newman, E., Fried, I. (2003). Cellular networks underlying human spatial navigation, Nature, 425, 184-188.

Etienne, A.S., Maurer, R., Seguinot, V. (1996). Path integration in mammals and its interaction with visual landmarks, The Journal of Experimental Biology, 199, 201-209

Fentress, J.C., Stanfield, B.B., Cowan, W.M. (1981). Observation on the development of the striatum in mice and rats, Anatomical Embryology, 163(3), 275-98.

Fyhn, M., Molden, S., Witter, M.P., Moser, E.I., Moser, M.B. (2004). Spatial representation in the entorhinal cortex, Science, 305, 1258-1264.

Graybiel, A.M., and Ragsdale, C.W. (1978). Histochemically distinct compartments in the striatum of human, monkey and cat demonstrated by acetylcholinesterase staining, Proceedings of the National Academy of Science, USA, 75, 5723-5726.

Graybiel, A.M. (1990). Neurotransmitters and neuromodulators in the basal ganglia, Trends in Neurosciences, 13, 244-254.

Heimer, L., Alheid, G. F., Zaborszky, L. (1985). Basal ganglia. In G. Paxinos (Ed.), The rat nervous system: Volume I. Forbrain and midbrain (pp. 37-86). Sydney: Academic Press.

Hoffman, D.C., West, T.E.G., Wise, R.A. (1991). Ventral pallidal microinjections of receptor-selective opioid agonists produce differential effects on circling and locomotor activity in rats, Brain Research, 550, 205-212.

Holahan, M.R., Taverna, F.A., Emrich, S.M., Louis, M., Muller, R.U., Roder, J.C., McDonald, R.J. (2005) Impairment in long-term retention but not short-term performance on a water maze reversal task following hippocampal or mediodorsal striatal N-methyl-D-aspartate receptor blockade, Behavioural Neuroscience, 119(6), 1563-71.

Holmes, E. J., Jacobson, S., Stein, B. M. Butters, N. (1983). Ablations of the mammillary nuclei in monkeys: effects on postoperative memory, Experimental Neurology, $81,97-113$. 
Hull, C. (1943). Principles of Behavior. New York: Appleton-Century-Crofts.

Kandel, E., Schwartz, J., Jessell, T. (2000). Principles of Neural Science $4^{\text {th }}$ ed. Montreal: McGraw-Hill.

Kandel, E.R. (2001). The molecular biology of memory storage: a dialogue between genes and synapses. Science, 294(5544), 1030-8.

Knierim, J.J. (2006). Neural representations of location outside the hippocampus, Learning and memory, 13, 405-415

Krebs, M., Trovero, F., Desban, M., Gauchy, C., Glowinski, J., \& Kemel, M. (1991). Distinct presynaptic regulation of dopamine release through NMDA receptors in striosome- and matrix-enriched areas of the rat striatum, Journal of Neuroscience, $11,1256-1262$.

Luine, V., Martinez, C., Villegas, M., McEwen, B.S. (1994) Repeated stress causes reversible impairments of spatial memory performance, Brain Research, 639, $167-170$.

McDonald, R.J., Hong, N.S., Devan, B.D. (2004). The challenges of understanding mammalian cognition and memory-based behaviours: an interactive learning and memory systems approach, Neuroscience Biobehavioural Reviews, 28(7), 719-45.

McDonald, R. J., \& White, N. M. (1994). Parallel information processing in the water maze: Evidence for independent memory systems involving dorsal striatum and hippocampus, Behavioral and Neural Biology, 61, 260-270.

McDonald, R. J., \& White, N. M. (1993). A triple dissociation of memory systems: Hippocampus, amygdala, and dorsal striatum. Behavioral Neuroscience, 107, 322.

McLay, R.N., Freeman, S.M., Zadina, J.E. (1998) Chronic corticosterone impairs memory performance in the Barnes maze, Physiology and Behaviour, 63, 933937.

Matthies, H. (1989). Neurobiological aspects of learning and memory, Annual Review of Psychology, 40, 381-404.

Milner, B., Squire, L.R., Kandel, E.R. (1998). Cognitive neuroscience and the study of memory, Neuron, 20, 445- 468.

Milner, B. (1970). Memory and the temporal regions of the brain. In K.H. Pribram and D.E. Broadbent (Eds.) Biology of Memory. New York: Academic Press. 
Mizoguchi, K., Yuzurihara, M., Ishige, A., Sasaki, H., Chui, D., Tabira, T. (2000) Chronic stress induces impairment of spatial working memory and of prefrontal dopaminergic dysfunction, Journal of Neuroscience, 20, 1568-1574.

Morris, R. (1984). Developments of a water-maze procedure for studying spatial learning in the rat, Journal of Neuroscience Methods, 11(1), 47-60.

Nauta, W.J.H. (1979). A proposed conceptual reorganization of the basal ganglia and telencephalon, Neuroscience, 4, 1875-1881.

Nolte, J. (1993). The Human Brain: an introduction to its functional anatomy. Missouri: Mosby-Year Book, Inc.

O’Keefe, J. and Dostrovsky, J. (1971). The hippocampus as a spatial map. Preliminary evidence from unit activity in the freely-moving rat, Brain Research, 34(1), 171-5.

O'Keefe, J., Nadel, L. (1978) The Hippocampus as a Cognitive Map, Oxford: Oxford University Press.

O'keefe, J. (1993). Hippocampus, theta, and spatial memory, Current Opinion in Neurobiology, 3(6), 917-24.

Packard, M.G., and Knowlton, B.J. (2002). Learning and Memory Functions of the Basal Ganglia, Annual Reviews Neuroscience, 25, 563-593

Parent, A. Sato, F., Wu, Y., Gauthier, J., Levesque, M., Parent, M. (2000). Organization of the basal ganglia: the importance of axonal collateralization, Trends in Neuroscience, 23, S20-S27.

Pear, J. (2001). The Science of Learning. Ann Arbour, MI: Edwards Brothers

Penfield, W., and Milner, B. (1958). Memory deficits induced by bilateral lesions in the hippocampal zone, American Medical Association Archives of Neurological Psychiatry, 79, 475-497.

Przewłocka, B., Lasoń, W., Turchan, J., de Bruin, N., van Luijtelaar, G., Przewłocki, R., Coenen, A. (1998). Anatomical and functional aspects of mu opioid receptors in epileptic WAG/Rij rats, Epilepsy Research, 29(2), 167-73.

Quirk, G.J., Muller, R.U., Kubie, J.L., Ranck, J. (1992). The positional firing properties of medial entorhinal neurons: Description and comparison with hippocampal place cells, Journal of Neuroscience. 12, 1945-1963.

Saucier, D and Cain, D. (1995). Spatial learning without NMDA receptor dependent long term potentiation, Nature, 378, 186-189 
Schroeder, J.E., Fischbach, P.S., Zheng, D., McCleskey, E.W. (1991). Activation of $\mu-$ opioid receptors inhibits transient high- and low-threshold Ca2+ currents, but spares a sustained current, Neuron, 6(1), 13-20.

Scoville, W.B., Milner, B. (1957). Loss of recent memory after bilateral hippocampal lesions, Journal of Neurology, Neurosurgery and Psychiatry, 20, 11-21

Segal, M. (1988). Effects of $\mu$ - opioid receptor activation in rat hippocampal slice,_NIDA Research Monographs, 82, 133-45.

Sharp, P.E. (1996). Multiple spatial/behavioral correlates for cells in the rat postsubiculum: Multiple regression analysis and comparison to other hippocampal areas, Cerebral Cortex, 6, 238-259.

Teyler, T.J., Discenna, P. (1984). Long-term potentiation as a candidate mnemonic device, Brain Research, 319(1), 15-28.

Thomasy, S.M., Moeller, B.C., Stanley, S.D. (2007). Comparison of opioid receptor binding in horse, guinea pig, and rat cerebral cortex and cerebellum, Veterinary Anaesthesia and Analgesia, 34(5), 351-8.

Tolman, E.C., and Honzik, C.H., (1930). Introduction and removal of reward and maze performance in rats, Publications in Psychology, 4, 257-275.

Tolman, E.C. (1932). Purposive behavior in animals and men. New York: Century.

Tolman, E.C. (1948). Cognitive Maps in Rats and Men, The Psychological Review, 55(4), 189-208.

Vann, S.D., Aggleton, J.P. (2004). The mammillary bodies: two memory systems in one? Nature Reviews Neuroscience, 5, 35-44.

Voorn, P., Vanderschuren, L.J.M.J., Groenewegen, H.J., Robbins, T.W., Pennartz, C.M.A. (2004). Putting a spin on the dorsal-ventral divide of the striatum, Trends in Neurosciences, $27(8), 468-474$.

Wang, H., Moriwaki, A., Wang, J.B., Uhl, G.R., Pickel, V.M. (1997) Ultrastructural immunocytochemical localization of $\mu$-opioid receptors in dendritic targets of dopaminergic terminals in the rat caudate-putamen nucleus, Neuroscience, 81 , 757-771

Wichmann, T., and DeLong, M.R. (1996). Functional and pathophysiological models of the basal ganglia, Current Opinions in Neurobiology, 6, 751-758. 
Whishaw, I.Q., Cassel, J.C., Jarrard, L.E. (1995). Rats with fimbria-fornix lesions display a place response in a swimming pool: A dissociation between getting there and knowing where, Journal of Nuroscience, 15, 5779-5788.

Whishaw, I.Q., and Jarrard, L.E. (1996). Evidence for extrahippocampal involvement in place learning and hippocampal involvement in path integration, Hippocampus, 6, 513-524.

White, N.M., and Hiroi, N. (1998). Preferential localization of self-stimulation sites in striosomes/patches in the rat striatum, Proceedings of the National Academies of Science, 95(11), 6486-91.

White, N.M., Holahan, M.R., Goffaux, P. (2003). Involuntary, unreinforced (pure) spatial learning is impaired by fimbria-fornix but not by dorsal hippocampus lesions, Hippocampus, 13(3), 324-33.

Will, M.J., Pratt, W.E., Kelley, A.E. (2006). Pharmacological characterization of high-fat feeding induced by opioid stimulation of the ventral striatum, Physiology and Behaviour, 30; 89(2), 226-34.

Wilson, C.J., Chang, H.T., Kitai, S.T. (1990). Firing patterns and synaptic potentials of identified giant aspiny interneurons in the rat neostriatum, Journal of Neuroscience, 10, 508-519.

Wilson, M.A., McNaughton, N.B.L (1993). Dynamics of the Hippocampal Ensemble Code for Space, Science, 261, 1055-1058.

Yeshenko, O., Guazzelli, A., Mizumori, S.J. (2004). Context-dependent reorganization of spatial and movement representations by simultaneously recorded hippocampal and striatal neurons during performance of allocentric and egocentric tasks, Behavioural Neuroscience, 118, 751-769.

Zernig, G., Harbig, P., Weiskirchner, I., Auffinger, M., Wakonigg, G., Saria, A. (2002) Reinforcing effect of subcutaneous morphine in a modified Ettenberg runway, Journal of Molecular Neuroscience, 18(1-2), 135-42.

Zhang, M., Gosnell, B.A., Kelley, A.E. (1998). Intake of high-fat food is selectively enhanced by mu-opioid receptor stimulation within the nucleus accumbens, Journal of Pharmacology and Experimental Therapeutics, 285(2), 908-14.

Zhou, T.L., Tamura, R., Kuriwaki, J., Ono, T. (1999). Comparison of medial and lateral septal neuron activity during performance of spatial tasks in rats, Hippocampus, 9 , 220-234 